- Monogràfic -

\title{
MEDICAMENTOS Y CAMBIO CLIMÁTICO: EL RÉGIMEN JURÍDICO DE LA GESTIÓN AMBIENTAL DE LOS MEDICAMENTOS, SUS RESIDUOS Y SUS ENVASES
}

\section{DRUGS AND CLIMATE CHANGE: THE LEGAL REGIME FOR THE ENVIRONMENTAL MANAGEMENT OF DRUGS, THEIR WASTE AND THEIR PACKAGING}

\author{
LUIS SARRATO MARTÍNEZ \\ Profesor asociado doctor de Derecho Administrativo \\ Universidad Pública de Navarra \\ luis.sarrato@unavarra.es
}

Fecha de recepción: 14 de octubre de 2021

Fecha de aceptación: 2 de noviembre de 2021

RESUMEN: En este trabajo se analizan las relaciones existentes entre el fenómeno del cambio climático y los medicamentos. Para ello, y partiendo de un planteamiento general, se analiza de forma preliminar el impacto ambiental de la industria farmacéutica y de la fabricación industrial de medicamentos dentro del contexto global industrial, con especial referencia a las posibles repercusiones en la industria farmacéutica de la nueva legislación española sobre cambio climático y residuos. Seguidamente, se efectúa una delimitación conceptual del medicamento como producto susceptible de convertirse en residuo, lo que conduce a analizar la normativa aplicable, así como el papel que juega la gestión de medicamentos, de sus residuos y de sus envases como herramienta para la lucha contra el cambio climático. Finalmente, se formulan unas breves conclusiones.

RESUM: En aquest treball s'analitzen les relacions existents entre el fenomen de I'canvi climàtic i els medicaments. Per a això, i partint d'un plantejament general, s'analitza de forma preliminar l'impacte ambiental de la indústria 
farmacèutica i de la fabricació industrial de medicaments dins de l'context global industrial, amb especial referència a les possibles repercussions en la indústria farmacèutica de la nova legislació espanyola sobre canvi climàtic. Seguidament, s'efectua una delimitació conceptual de l'medicament com a producte susceptible de convertir-se en residu, el que condueix a analitzar la normativa aplicable, així com el paper que juga la gestió de medicaments, dels seus residus i dels seus envasos com a eina per a la lluita contra el canvi climàtic. Finalment, es formulen unes breus conclusions.

ABSTRACT: This work analyzes the relationships between the phenomenon of climate change and drugs. To do this, and starting from a general approach, the environmental impact of the pharmaceutical industry and the industrial manufacture of medicines is analyzed in a preliminary way within the global industrial context, with special reference to the possible repercussions on the pharmaceutical industry of the new legislation. Spanish on climate change. Next, a conceptual delimitation of the drug is made as a product capable of becoming waste, which leads to analyze the applicable regulations, as well as the role that the management of drugs, their waste and their packaging plays as a tool for the fight against climate change. Finally, some brief conclusions are formulated.

PALABRAS CLAVE: Industria farmacéutica - Medicamentos - Cambio climático - Desarrollo sostenible - Gestión de residuos

PARAULES CLAU: Indústria farmacèutica - Medicaments - Canvi climàtic Desenvolupament sostenible - Gestió de residus

KEY WORDS: Pharmaceutical industry - Drugs - Climate change Sustainable development - Waste management

SUMARIO: I. PLANTEAMIENTO GENERAL SOBRE LA RELACIÓN ENTRE LOS MEDICAMENTOS Y EL CAMBIO CLIMÁTICO. 1. El impacto ambiental de la industria farmacéutica. 2. La fabricación industrial de medicamentos ante el fenómeno del cambio climático. a) Un apunte preliminar sobre la intervención administrativa durante el ciclo de vida del medicamento y su vínculo con la protección medioambiental. b) Industria farmacéutica y nueva legislación española sobre cambio climático. III. EL MEDICAMENTO COMO PRODUCTO SUSCEPTIBLE DE CONVERTIRSE EN RESIDUO: DELIMITACIÓN CONCEPTUAL Y MARCO JURÍDICO APLICABLE. 1. El medicamento como residuo: un doble marco normativo. a) Entronque del concepto jurídico de medicamento con su dimensión medioambiental. b) La legislación ambiental. c) La legislación sanitaria y farmacéutica. IV. LA GESTIÓN AMBIENTAL 
DE MEDICAMENTOS, RESIDUOS DE MEDICAMENTOS Y SUS ENVASES COMO HERRAMIENTAS PARA LA LUCHA CONTRA EL CAMBIO CLIMÁTICO. 1. Reciclaje farmacéutico y sostenibilidad ambiental en el contexto de una economía circular. 2. La Responsabilidad Ampliada del Productor (RAP) aplicada al ciclo de vida del medicamento. a) Hacia una producción de medicamentos más verde y sostenible. b) La Responsabilidad Ampliada del Productor (RAP) en el ámbito de la gestión de los residuos de medicamentos y sus envases. c) Autorregulación y Responsabilidad Social Corporativa (RSC) de la industria farmacéutica como componentes que permiten el diseño de estrategias sostenibles. V. A MODO DE CONCLUSIÓN. VI. BIBLIOGRAFÍA.

\section{PLANTEAMIENTO GeNERAL SOBRE LA RELACIÓN ENTRE LOS MEDICAMENTOS Y EL CAMBIO CLIMÁTICO.}

\section{El impacto ambiental de la industria farmacéutica.}

Como es sobradamente conocido, el sector industrial desarrolla el proceso de conversión de materias primas, todas ellas de muy diversas procedencias, en productos elaborados. Teniendo en cuenta la evolución experimentada a raíz del proceso de industrialización, en los tiempos actuales la industria constituye la base de la economía de muchos países, en la medida en que no solamente constituye una rica fuente de empleo, sino que también posibilita a las empresas la obtención de ingresos en sus transacciones comerciales, y que puedan así maximizar sus beneficios ${ }^{1}$.

Es obvio que las actividades industriales, como prácticamente todas las actividades desarrolladas por el ser humano, traen consigo un impacto sobre el medio que le rodea ${ }^{2}$. Si bien la industria en su conjunto se configura como un ingrediente crucial de la economía, no podemos olvidar el impacto ambiental que su actividad tiene para el medio ambiente. La tradicional problemática relativa a los procesos industriales y sus efectos devastadores sobre el medio ambiente y los recursos naturales, pone encima de la mesa una de las principales temáticas que enfrenta actualmente la sociedad contemporánea: la relación entre la

\footnotetext{
${ }^{1}$ Sobre la contribución de la industria farmacéutica a la economía, resulta de interés el reciente Informe elaborado por la Fundación Weber: El valor del medicamento desde una perspectiva social, Madrid, marzo de 2021, disponible en la página web de Farmaindustria: https://www.farmaindustria.es [online, consultado 26-09-2021].

2 A lo largo de la Historia, se han producido sucesos con un impacto importante y mediático (Chernobil, Bhopal, etc.), que han propiciado cambios en la legislación industrial a nivel mundial; si bien en otras ocasiones el impacto es mucho más localizado y no tan mediático, pero persistente en el tiempo por la continuidad de la actividad que lo provoca, como así sucede en numerosas actividades industriales, incluida la industria farmacéutica. Vid. José Daniel Escrig Zaragozá: "El impacto ambiental de las actividades industriales: el cambio necesario", Universidad Internacional de Andalucía, España, 2008 [online, consultado 25-09-2021].
} 
industria y el medio ambiente, y el necesario equilibrio que debe existir entre ambos. Con el propósito de conjugar adecuadamente el desarrollo industrial y una adecuada protección medioambiental, se han venido desarrollando instrumentos normativos a diferentes niveles, así como políticas de prevención de la contaminación. Como botón de muestra, la normativa sobre prevención y el control integrado de la contaminación, sobre la prevención y gestión de residuos, sobre medidas para la reducción de las emisiones nacionales de determinados contaminantes atmosféricos, 0 sobre responsabilidad medioambiental, son tan solo algunos de los ejemplos que podemos mencionar.

Resulta un tanto paradójico que, por un lado, la industria esté indisolublemente unida al desarrollo de la sociedad y de la mejora de la calidad de vida de las personas, -precisamente por su papel dinamizador de la economía-, y, por otro lado, el acelerado avance de la industrialización haya generado una serie de cambios y aspectos adversos sobre el medio ambiente. De modo especial, cabe resaltar un cambio significativo en los patrones climáticos por las emisiones industriales de gases de efecto invernadero (GEI), que tienen como fuentes principales las actividades energéticas, industriales y agrícolas ${ }^{3}$. Estos gases han provocado un calentamiento global causante de innumerables desajustes a nivel físico, biológico y poblacional en todo el planeta 4 . Todo ello explica que el cambio climático sea hoy una realidad de ineludible estudio por parte de la ciencia, incluida la ciencia jurídica. No cabe duda que, sin perjuicio de ciertas controversias científicas acerca de sus concretas causas, constituye uno de los principales retos estratégicos al que las industrias a nivel mundial se están

\footnotetext{
3 Según señala Miren Sarasíbar Iriarte: Régimen jurídico del cambio climático, Lex Nova, Valladolid, 2006, p. 94, "las principales fuentes de estos gases se encuentran las actividades energéticas (producción, quema, transporte, distribución y almacenamiento de combustibles), las actividades industriales (industrias del carbón y del acero e industrias químicas, utilización de disolventes y otros productos que contengan compuestos orgánicos volátiles) y las actividades agrícolas (cambios en el uso de la tierra y producción de desechos y residuos, fundamentalmente)".

${ }^{4}$ Los GEl generados por la industria durante el último siglo y medio más significativos son el dióxido de carbono, metano y óxido nitroso, siendo el primero el gas más importante, por los valores estadísticos que se han venido registrando. Vid. Roberto Olvi Arévalo Moscoso: "La Industria y sus efectos en el cambio climático global", Revista Científica de InvestigaciónActualización del Mundo de las Ciencias, Vol. 2, núm. 2, junio, 2018, pp. 595-611.
} 
enfrentando para proteger nuestro futuro y el del planeta, dada la aceleración del calentamiento global de la tierra y los problemas derivados de la emisión de GEI.

De entre todas las actividades industriales, la actividad de fabricación y producción industrial de medicamentos a gran escala no permanece -ni debe permanecer- ajena a esta problemática. Es una realidad innegable que la industria farmacéutica, de forma paralela a su importante contribución de aliviar el dolor y paliar la enfermedad de las personas a través de los productos innovadores que produce, ha venido contribuyendo ampliamente al calentamiento global por la emisión de GEI. En España, es la industria el principal agente emisor de GEl, y según las cuentas medioambientales ofrecidas por el Instituto Nacional de Estadística (INE) correspondientes al año 20195, este tipo de gases aumentan un $2,6 \%$ en 2017 y se sitúan en 344,0 millones de toneladas de $\mathrm{CO}_{2}$ equivalente, principal gas de efecto invernadero, todo ello según los datos confeccionados por el INE. Asimismo, el sector industrial de la fabricación de medicamentos y productos farmacéuticos ha emitido un total de 836 miles de toneladas de $\mathrm{CO}_{2}$ de GEI durante el año 2019, tal y como reflejan los datos consultados en la página web del INE, la cual permite efectuar una consulta de datos por sector y por año dentro del período comprendido entre los años 2008 y 20196. La Unión Europea (UE), consciente de la problemática que genera dichas emisiones en el espacio europeo, mantiene su ambicioso objetivo de alcanzar la neutralidad en carbono para 2050, es decir, lograr una economía con cero emisiones de GEl; objetivo que forma parte del núcleo del Pacto Verde Europeo y está en consonancia con el compromiso de la UE con la acción climática global en virtud del Acuerdo de París ${ }^{7}$. No obstante, conviene matizar

\footnotetext{
${ }^{5}$ Vid. el Informe elaborado por el INE: España en cifras 2019, p. 7, disponible en la página web oficial del INE: https://www.ine.es [online, consultado 26-09-2021].

${ }^{6}$ Los datos de emisiones a la atmósfera por ramas de actividad, conforme a los parámetros ya señalados, están disponibles en la página web oficial del INE: https://www.ine.es [online, consultado 25-09-2021].

${ }^{7}$ La UE se ha fijado objetivos con la finalidad de reducir progresivamente sus emisiones de gases de efecto invernadero hasta 2050, y así alcanzar una sociedad resistente al cambio climático y plenamente adaptada a sus efectos inevitables; para lo cual supervisa sus progresos en la reducción de las emisiones mediante actividades periódicas de seguimiento y elaboración de informes. En este sentido, pueden consultarse las "estrategias y objetivos climáticos" disponibles en la página web oficial: https://ec.europa.eu/clima/policies/strategies es [online, consultado 2509-2021].
} 
la complejidad que reviste el proceso de descarbonización de las industrias químicas y farmacéuticas, ya que, si finalmente no resultase posible reducir sus emisiones de GEI a cero, sería necesario compensar el resto de sus emisiones para lograr la neutralidad en carbono, lo que plantea uno de los mayores desafíos a futuro. Desde esta tesitura, la digitalización de estos mercados es una valiosa herramienta para conseguir una mayor transparencia y eficiencia en la monitorización de los impactos ambientales y en la contabilidad del carbono en las industrias de este sector, contribuyendo así a los objetivos globales de la lucha contra el cambio climático.

Dicho lo anterior, hay que señalar que las mayores instalaciones industriales en el territorio de la UE no solamente generan buena parte de las emisiones totales de importantes contaminantes atmosféricos y $\mathrm{GEI}^{8}$, sino que materializan de forma adicional otros impactos de índole ambiental, como por ejemplo la emisión de contaminantes a las aguas y al suelo, la producción de residuos y el consumo de energía ${ }^{9}$. A ello hemos de añadir la problemática que suscita el medicamento como residuo, que supone la entrada y permanencia en el medio ambiente de contaminantes emergentes, incluidos compuestos de naturaleza química, y de origen diverso, hasta el punto de que existen diversos estudios científicos que han detectado y analizado la presencia de residuos de medicamentos en aguas residuales de diferentes tipos (urbanas, hospitalarias, industriales, superficiales, y las de origen agrícola o ganadero), pero también en suelo, aire, etc., en concentraciones que varían en función del producto farmacéutico y del tipo y la proximidad de las fuentes, con las perniciosas consecuencias que, sin duda alguna, todo ello acarrea no solo para el medio ambiente (comprometiendo

\footnotetext{
${ }^{8}$ Sobre la problemática jurídica que plantean los GEI y la intervención administrativa que se proyecta sobre esta cuestión, nos remitimos a: Juan Antonio Hernández Corchete, "Los Hábitos Energéticos en el horizonte del desarrollo sostenible: una panorámica de los esfuerzos por invertir la tendencia de emisión de GEI como medio de atajar el preocupante proceso de cambio climático", en: Sebastián Félix Utrera Caro y José Luis Piñar Mañas (Coords.): Desarrollo Sostenible y Protección del Medio Ambiente, Civitas, Madrid, 2002, pp. 311-318. También puede consultarse: Ricardo Rivero Ortega: "Los gases de efecto invernadero: Inspección y control de riesgos en materia de emisiones contaminantes", Noticias de la Unión Europea, núm. 258, 2006 (Ejemplar dedicado a: Gases de Efecto Invernadero), pp. 79-84.

${ }^{9}$ Sobre la relación entre el sector de la energía y el medioambiente, aludiendo a los desafíos que plantea el cambio climático, vid. Martín María Razquin Lizarraga: "Energía y Medio Ambiente: marco normativo y aplicación judicial”, Revista Aranzadi de Derecho Ambiental, núm. 21, 2012, pp. 23-60.
} 
seriamente la supervivencia de la flora y la fauna en general, y de numerosas especies animales en particular), sino también para la salud de las personas. La contaminación, principalmente, de aguas y suelos, por la presencia de sustancias farmacéuticas, incluso combinadas (donde cabe encontrar determinados analgésicos, antimicrobianos, antidepresivos, anticonceptivos, antiparasitarios, etc. $)^{10}$, ha ido favoreciendo la toma de conciencia de la industria farmacéutica que, siguiendo los parámetros de la UE, va manifestando su compromiso a la hora de desarrollar productos farmacéuticos innovadores que presenten un riesgo menor para el medio ambiente, de implementar mejores técnicas de reciclado de aguas residuales, y de utilizar métodos de fabricación de medicamentos que sean más respetuosos con el medio ambiente.

\section{La fabricación industrial de medicamentos ante el fenómeno del cambio climático.}

\section{a) Un apunte preliminar sobre la intervención administrativa durante el ciclo de vida del medicamento y su vínculo con la protección medioambiental.}

Como punto de partida, cabe resaltar, por una parte, la peculiaridad del sector farmacéutico dentro del ámbito industrial y, por otra, la particularidad del medicamento como producto en el marco del contexto global industrial. El sector farmacéutico es un componente básico de los sistemas sanitarios y su importancia se debe a varios factores que, siguiendo al profesor Lobo,

\footnotetext{
${ }^{10}$ Así lo señala la "Comunicación de la Comisión al Parlamento Europeo, al Consejo y al Comité Económico y Social Europeo. Enfoque estratégico de la Unión Europea en materia de productos farmacéuticos en el medio ambiente", COM (2019) 128 final, Bruselas, 11-03-2019, p. 2. Esta Comunicación explica que, tal y como se exige en el artículo 8 quater de la Directiva sobre sustancias prioritarias (Directiva 2008/105/CE, modificada por la Directiva 2013/39/UE), "el enfoque estratégico debe ir seguido, en su caso, de propuestas de medidas que deben adoptarse a escala de la Unión o de los Estados miembros para tratar las consecuencias que las sustancias farmacéuticas pueden tener en el medio ambiente, a fin de reducir el vertido, las emisiones y la fuga de estas sustancias en el medio acuático, teniendo en cuenta las necesidades de salud pública y la relación coste/eficacia de las medidas propuestas. Para que las medidas sean eficaces y den lugar a una distribución equitativa de los esfuerzos, no deberían consistir únicamente en controles en la parte final de los procesos (por ejemplo, mejora del tratamiento de las aguas residuales), sino abordar también las fuentes en las que se originan las emisiones (por ejemplo, la producción y el uso) y contemplar tanto el medio terrestre como el medio acuático". En este sentido, la mencionada Comunicación establece seis ámbitos de actuación y varias actuaciones concretas relativas a posibles medidas.
} 
mencionaremos a continuación ${ }^{11}$. En primer lugar, porque contribuye de forma esencial a mejorar la salud de los ciudadanos. En segundo lugar, es uno de los principales motores de la innovación, de tal forma que la investigación y el desarrollo de nuevos medicamentos desempeña un papel central en las actividades de la industria farmacéutica, el gran sector de la $1+D+i$ de los medicamentos, que implica estudios continuos e inversión constantes en conocimiento ${ }^{12}$. Vale la pena señalar que el sector farmacéutico es un sector de alta intensidad en I+D, dado que la llegada de nuevos medicamentos no es posible sin una gran inversión previa en investigación. Así, este sector se sitúa entre los sectores líderes en inversión en I+D, posicionándose como el sector industrial con mayor inversión en I+D+i en España (un 19\% de gasto), al haber destinado 1.303 millones de euros en el año $2018^{13}$. En tercer lugar, es un importante sector de la economía nacional, que contribuye a generar renta y empleo, y con seguridad lo hará más en el futuro. Finalmente, debido a su aportación en términos de salud y bienestar, los Estados dedican una parte nada desdeñable de sus gastos a asegurar a sus ciudadanos la disponibilidad de medicamentos ${ }^{14}$.

A renglón seguido, tal y como ya se ha dicho, el medicamento constituye un producto singular, que posee unas características intrínsecas que lo hacen diferenciarse de otros productos de consumo ordinario. Sin perder de vista las especificidades del medicamento dentro del universo sanitario, es importante destacar que constituye uno de los elementos que más ha contribuido a los

\footnotetext{
11 Vid. Félix Lobo Aleu: "Introducción a la regulación del sector farmacéutico en España", en: Jordi Faus Santasusana y José Vida Fernández (Dirs.): Tratado de Derecho Farmacéutico, Thomson Reuters Aranzadi, Pamplona, 2017, p. 79 y ss.

12 La I+D+i es un proceso extremadamente complejo, que requiere mucho tiempo e inversión. Téngase en cuenta que se pueden llegar a identificar hasta 10.000 compuestos como posibles tratamientos y sólo uno de ellos llegará a convertirse en un medicamento autorizado. Al respecto, vid. Jesús Flórez Belledo (Dir.): Farmacología Humana, Masson, Barcelona, 2005, p. 202.

${ }^{13}$ Así lo refleja el Informe elaborado en marzo de 2021 por la Fundación Weber: El valor del medicamento..., cit. [online, consultado 26-09-2021].

${ }^{14}$ Tal y como señala el profesor Lobo, "la fenomenal expansión de las ventas de medicamentos a hospitales, o de su gasto, es uno de los hechos clave del mercado farmacéutico español en los últimos años", y ello "responde a la evolución de la tecnología farmacéutica, que genera actualmente muchos productos de manejo complejo, como los biotecnológicos". Vid. Félix Lobo Aleu: "Introducción a la regulación del sector farmacéutico en España", en: Jordi Faus Santasusana y José Vida Fernández (Dirs.): Tratado de Derecho..., cit., p. 91.
} 
cambios demográficos históricos, no solo disminuyendo la mortalidad y aumentando la esperanza de vida, sino también mejorando considerablemente las condiciones de vida de millones de personas en el mundo, y ello gracias al desarrollo de la industria farmacéutica. Actualmente, la correcta administración de medicamentos permite incrementar años de vida; una posibilidad jamás pensada siglos atrás, cuando se recurría al mundo vegetal para paliar la enfermedad y aliviar el dolor.

Pero si bien resulta indiscutible que el medicamento constituye una herramienta especialmente útil por su singularidad, a su vez, presenta riesgos reales y potenciales no solamente para las personas ${ }^{15}$, sino también para el medio ambiente. La industria químico-farmacéutica y su volumen de producción resulta considerable en términos económicos. Muchas de las empresas del sector del medicamento y de sus sectores complementarios figuran en el ranking de las más grandes del mundo. Dada su magnitud, no es arriesgado pensar que el impacto medioambiental de este sector productivo sea mayor, en términos comparativos, que el de otro tipo de sectores. En el caso concreto de la industria del medicamento, dicho impacto puede tener lugar en diferentes fases 0 momentos temporales: diseño, síntesis y evaluación del medicamento; producción del principio activo; fabricación del producto, e incluso el impacto también podrá materializarse en las posteriores fases de uso del medicamento y a través de su eliminación o desecho.

En este sentido, podríamos afirmar que el binomio "salud" y "medio ambiente" son las dos caras de la misma moneda, por lo que será de vital importancia buscar y encontrar siempre el necesario equilibrio entre la salvaguarda del medio ambiente y la salud, un objetivo que nace en primer término de la fase previa de planificación, posterior diseño y ulterior fabricación del medicamento, y que solo culminará cuando éste finalice completamente su ciclo de vida o existencia.

\footnotetext{
${ }^{15}$ La industria farmacéutica, y en especial las empresas que fabrican medicamentos, es decir, los laboratorios farmacéuticos, también están sujetos a responsabilidad debido al deterioro que pueden sufrir los medicamentos que fabrican y que en ocasiones pueden producir alteraciones en la salud de los pacientes que los consumen, e incluso, a veces, la muerte de los mismos. Al respecto, vid. Luis Sarrato Martínez: La responsabilidad administrativa, civil y penal en el ámbito del medicamento, Thomson Reuters- Aranzadi, Pamplona, 2014.
} 
Como es bien sabido, el medicamento es un bien sanitario, objeto de control e intervención administrativa durante todas las fases de su vida ${ }^{16}$ : experimentación, fabricación, patente, distribución, comercialización, prescripción, publicidad, dispensación y posterior régimen de farmacovigilancia, no quedando ninguna de las fases de dicho ciclo de vida plenamente libre de intervención ${ }^{17}$. De esta forma, dicho control es particularmente intenso por parte de la Administración para comprobar que en el nuevo producto farmacéutico concurren las necesarias garantías de calidad, seguridad y eficacia, y así garantizar un uso seguro y eficaz de los medicamentos para cada uno de los pacientes a los que se les administren. Por esa misma razón se somete a los medicamentos a autorización para su puesta en circulación. Esta intervención es del todo necesaria y relevante para establecer las reglas que permitan ordenar el sector y reforzar los mecanismos de reglamentación farmacéutica, y, siguiendo al profesor Ezquerra Huerva, se justifica en la necesidad de que la Administración controle el acceso de los ciudadanos a unos productos -los medicamentos-, intrínsecamente peligrosos ${ }^{18}$. El grado de intervención administrativa que se da en los diferentes sectores de actividad económica e industrial y, por tanto, en el sector del medicamento, se traduce en una mayor o menor intensidad de las obligaciones que se imponen a las empresas. Estas obligaciones pueden ser de índole económica (la intervención administrativa en los precios y condiciones económicas de los medicamentos), de índole sanitaria (la intervención administrativa durante todo el ciclo de vida del medicamento, encaminada a comprobar todos y cada uno de los requisitos que permitirán el otorgamiento de la autorización sanitaria y de comercialización, incluida la farmacovigilancia posterior), y también de índole medioambiental (la intervención

\footnotetext{
${ }^{16}$ En este sentido, Francisco Miguel Bombillar Sáenz: Intervención administrativa y régimen jurídico del medicamento en la Unión Europea, Tesis Doctoral, Universidad de Granada, 2010, p. 7.

17 Sobre las distintas modalidades de intervención administrativa durante el ciclo de vida del medicamento, vid. Luis Sarrato Martínez: Régimen jurídico-administrativo del medicamento, La Ley Wolters-Kluwer, Madrid, 2015, p. 294 y ss.; y Francisco Miguel Bombillar Sáenz: Intervención administrativa..., cit.

18 Vid. Antonio Ezquerra Huerva: "La Ordenación Farmacéutica", en: Juan María Pemán Gavin (Dir.): Derecho sanitario aragonés. Estudios sobre el marco jurídico de la sanidad en Aragón. Vol. II, Cortes de Aragón, Zaragoza, p. 324.
} 
administrativa encaminada a reducir el impacto ambiental de los medicamentos y productos farmacéuticos hasta el final de su ciclo de vida).

Ya en el plano medioambiental, la reglamentación de esta intervención administrativa exige necesariamente la adopción de una perspectiva integrada. El abordaje de la protección del medio ambiente en relación con los efectos nocivos de los medicamentos y los residuos de medicamentos de uso humano y veterinario, debe estar presidido por un enfoque que tome como punto de arranque la consideración del medio ambiente como un todo, lejos así de la superada óptica de la regulación ambiental que solamente tenga en consideración la perspectiva del medio objeto de protección (agua, aire, suelo) o del sector (residuos, fauna, flora, etc.) de forma aislada, la cual ya se ha demostrado que resulta ser limitada e insuficiente ${ }^{19}$. La necesidad de adoptar una perspectiva integrada no ha pasado inadvertida al legislador ambiental ${ }^{20}$. Este planteamiento no es nuevo, pues además de haber sido una postura asumida por la doctrina ${ }^{21}$, ha sido una recomendación internacional el fomento de la integración tanto de normas como de instituciones encargadas de velar por su cumplimiento. Hace ya treinta años, la Recomendación de la OCDE de 31 de enero de 1991, sobre "Control y prevención integrada de la contaminación del medio ambiente" invitaba a considerar como "un todo" los efectos externos sobre el medio ambiente de actividades y sustancias, así como a tener presente el entero ciclo de vida económico y ecológico de las sustancias, tanto desde la perspectiva de la reducción de riesgos, como del desarrollo y aplicación de medidas correctoras. Una vez más, y ante un problema serio de gran magnitud,

\footnotetext{
${ }^{19}$ En este sentido, vid. Borja López-Jurado Escribano y Ángel Ruiz de Apodaca Espinosa: La autorización ambiental integrada. Estudio sistemático de la Ley 16/2002, de prevención y control integrados de la contaminación, Civitas, Madrid, 2002, pp. 49-51. Asimismo, Ramón Martín Mateo: "El derecho de la atmósfera", RAP, núm. 121, Madrid, 1990, p. 90, señala: "se revela efectivamente necesario un enfoque global para el tratamiento de los problemas atmosféricos que responda al carácter integrado e interrelacionado de los factores implicados".
}

20 Así se ha puesto de manifiesto mediante determinadas técnicas de intervención ambiental, como, por ejemplo, la necesidad de obtención de una autorización por parte de los titulares de instalaciones industriales, grandes y medianas, de los sectores más importantes, tanto por su importancia económica, como laboral como ambiental, de tal forma que se integra en una sola autorización las de vertido, gestión de residuos, incineración, etc.

21 Así, Borja López-Jurado Escribano y Ángel Ruiz de Apodaca Espinosa: La autorización ambiental integrada..., cit., con cita de los autores Udo Di Fabio y Nigel Heigh: Integratives Umweltrecht, Berlín, 1998. 
está claro que el marco legal de acción frente al cambio climático no puede considerarse de forma aislada. Estamos ante un problema que exige igualmente la adopción de una perspectiva integrada, lo que obligará a examinar la operatividad de las recientes novedades legislativas al respecto, y de su futuro desarrollo reglamentario.

\section{b) Industria farmacéutica y nueva legislación española sobre cambio climático.}

Ya hemos advertido anteriormente que el cambio climático constituye un problema de primera magnitud, y supone una amenaza cierta para la preservación del ecosistema humano ${ }^{22}$, convirtiéndose en el centro actual de las preocupaciones ambientales. Además, existen otros muchos problemas ambientales adicionales de extrema gravedad (asociados en mayor o menor medida al cambio climático), como, por ejemplo, la progresiva e incesante pérdida de biodiversidad.

Ningún estudio científico puede determinar con exactitud ni los lugares en los que se van a producir los efectos del cambio climático ni su gravedad, ya que es impredecible concretar el grado de variación de la temperatura media global y, por tanto, qué y cómo serán los acontecimientos climáticos consecuencia de dicho incremento ${ }^{23}$. A esta realidad podemos añadir que los efectos sanitarios del cambio climático solamente se pueden medir de una forma aproximada.

Ante este escenario, desde la detección del problema del cambio climático mundial y sus evidencias, ha habido una reacción tanto por parte de la comunidad internacional, como por parte de las instituciones de la Unión Europea, dando lugar así a una serie de normas, políticas, estrategias, compromisos y protocolos destinados a combatir dicha problemática, que, dada su extensión, resulta imposible su abordaje en el presente trabajo. En el caso de España, los expertos coinciden en señalar que, por su situación geográfica y sus

\footnotetext{
22 Vid. Blanca Lozano Cutanda y Juan-Cruz Alli Turrillas: Administración y legislación ambiental, 5a ed., Dykinson, Madrid, 2009, p. 108.

${ }^{23}$ Vid. Teresa Parejo Navajas: "Gobernar el cambio climático", en: Luciano Parejo Alfonso (Dir.): El Derecho ante la innovación y los riesgos derivados del cambio climático, Tirant Lo Blanch, Valencia, 2015, p. 73.
} 
características socioeconómicas, es uno de los países de Europa más vulnerables al cambio climático ${ }^{24}$. Ello explica que en los últimos años se hayan intensificado notablemente las diferentes medidas y políticas públicas para mitigar el cambio climático y sus efectos sobre la salud y el medioambiente.

En lo que aquí nos interesa destacar, recientemente se ha aprobado la Ley 7/2021, de 20 de mayo, de Cambio Climático y Transición Energética ${ }^{25}$. Se trata de la primera Ley de cambio climático y transición energética de España, de tal forma que, marcando el inicio de un largo camino, supone un primer paso fundamental para articular a futuro el resto de políticas y medidas en esta materia. La Ley contiene un conjunto de medidas orientadas a las energías renovables, la eficiencia energética, la movilidad sostenible, la adaptación al cambio climático, la transición justa, o los recursos financieros para la lucha contra el cambio climático. El texto legal recoge los objetivos mínimos nacionales de reducción de emisiones de GEl, energías renovables y eficiencia energética de la economía española para los años 2030 y 205026. Además, la norma contempla como instrumentos de planificación para abordar la transición energética el Plan Nacional Integrado de Energía y Clima (PNIEC) y la Estrategia de Descarbonización a 2050 de la Economía Española. El primero debe recoger los objetivos sectoriales y las políticas y medidas para alcanzarlos de los sectores que participan en régimen de comercio de derechos de emisión, las grandes industrias y el sector eléctrico y los sectores difusos (agrario, forestal, transporte, residencial, institucional, comercial y de gases fluorados). Además, la Ley establece que el Plan Nacional de Adaptación al Cambio Climático (PNACC) es el instrumento de planificación para promover la acción coordinada

\footnotetext{
24 Unida a esa mayor vulnerabilidad, se ha afirmado que la Unión Europea es líder a escala mundial en la política de lucha contra el cambio climático. Vid. Juan Carlos Ciscar Martínez y Antonio Soria Ramírez: "La política climática", Papeles de la Economía Española, núm. 121/2009, pp. 45-53.

${ }^{25}$ BOE núm. 121, de 21-05-2021.

${ }^{26}$ Las emisiones del conjunto de la economía española en el año 2030 deberán reducirse en al menos un $23 \%$ respecto al año 1990 y se deberá alcanzar la neutralidad climática a más tardar en el año 2050. Además, en el año 2030 deberá alcanzarse una penetración de energías de origen renovable en el consumo de energía final de, al menos, un $42 \%$, un sistema eléctrico con, al menos, un $74 \%$ de generación a partir de energías de origen renovable y mejorar la eficiencia energética disminuyendo el consumo de energía primaria en, al menos, un 39,5\% con respecto a la línea de base conforme a normativa comunitaria.
} 
frente a los efectos del cambio climático. Así, se prevé el establecimiento de objetivos estratégicos y la definición de un sistema de indicadores de impactos y adaptación al cambio climático, así como la elaboración de informes de riesgo. Todo ello marca el inicio de un largo camino por recorrer.

Si bien la Ley supone un hito importante, en tanto piedra angular de un sistema encaminado a paliar el impacto del cambio climático, y por ello merece una valoración positiva, debe advertirse que nos encontramos ante una norma muy programática, y que adolece del grado de detalle que sería deseable. No hay más que observar las diferentes remisiones a normas reglamentarias, que serán las que en un futuro deberán desarrollar los contenidos en general, y desgranar de forma pormenorizada, por ejemplo, las concretas obligaciones que se impongan a las empresas, incluida la industria farmacéutica. Incluso adviértase la actual ausencia en el texto de la Ley de un régimen sancionador, lo que puede llegar a desdibujar los encomiables propósitos y objetivos perseguidos de manera ambiciosa por la Ley.

Sin perjuicio de las disposiciones de la norma que sean aplicables a la industria farmacéutica de igual modo que a cualquier otro tipo de empresa, lo cierto es que, a lo largo del texto de la misma, no se alude de forma concreta a la industria farmacéutica, ni tampoco se menciona de forma explícita el medicamento como producto susceptible de convertirse en residuo y su incidencia en la problemática que gira en torno al cambio climático. Pero de forma indirecta se vislumbran aspectos de clara incidencia, como así sucede con la gestión eficiente de los residuos, considerada por la Ley como un área estratégica para la mitigación de emisiones y para la transición energética, en cuya labor ya contamos con precedentes a la hora de efectuar la labor de gestión de los residuos de medicamentos y sus envases, como así lo hace en España la entidad privada SIGRE, tal y como más adelante se explicará.

\section{EL MEDICAMENTO COMO PRODUCTO SUSCEPTIBLE DE CONVERTIRSE EN RESIDUO: DELIMITACIÓN CONCEPTUAL Y MARCO JURÍDICO APLICABLE.}

\section{El medicamento como residuo: un doble marco normativo.}




\section{a) Entronque del concepto jurídico de medicamento con su dimensión medioambiental.}

La regulación del medicamento en el ordenamiento jurídico plantea numerosas y muy variadas cuestiones, que necesariamente deben ser abordadas de forma multidisciplinar, exigiendo a la postre la adopción de un enfoque integrado, tal y como se ha mencionado con anterioridad. Esa es la razón fundamental que explica la posibilidad de realizar una conceptualización técnica y jurídica del medicamento atendiendo a diferentes criterios. A la hora de determinar el concepto jurídico de medicamento, se pueden distinguir varios criterios diferenciales en función de los objetivos de salud pública perseguidos, y que se han ido perfilando por la jurisprudencia del TJUE a lo largo de las últimas décadas. La Directiva 2001/83/CE, en consonancia con el vigente RDLeg. 1/2015, de 24 de julio, por el que se aprueba el Texto Refundido de la Ley de Garantías y Uso Racional de los Medicamentos y Productos Sanitarios (LGURMPS), define "medicamento" en los siguientes términos:

"Toda sustancia o combinación de sustancias que se presente como poseedora de propiedades curativas o preventivas con respecto a las enfermedades humanas;

se considerarán asimismo medicamentos todas las sustancias o combinación de sustancias que puedan administrarse al hombre con el fin de establecer un diagnóstico médico o de restablecer, corregir o modificar las funciones fisiológicas del hombre"27.

Básicamente, la noción de medicamento en el Derecho europeo recoge dos criterios: una definición por la presentación y una definición por la función ${ }^{28}$. El

\footnotetext{
27 La definición europea de "medicamento" se contiene en el art. 1.2 de la Directiva 2001/83/CE del Parlamento Europeo y del Consejo, de 6 de noviembre de 2001, por la que se establece un código comunitario sobre medicamentos para uso humano (DOCE L 311/67, de 28-11-2001), y es sustancialmente coincidente con la definición de "medicamento" contenida en el art. 2 a) del Real Decreto Legislativo 1/2015, de 24 de julio, por el que se aprueba el Texto Refundido de la Ley de Garantías y Uso Racional de los Medicamentos y Productos Sanitarios (BOE núm. 177, de 25-07-2015).

28 Sobre el concepto jurídico de medicamento, vid.: vid. Francisco Miguel Bombillar Sáenz: Intervención administrativa..., cit.; Luis Sarrato Martínez: Régimen jurídico-administrativo..., cit..; José Vida Fernández: Concepto y Régimen Jurídico de los Medicamentos, Tirant lo Blanch, Valencia, 2015; y más recientemente, Alfonso Noguera Peña y Carlos Del Castillo Rodríguez:
} 
primer criterio (medicamento-indicación terapéutica) define al medicamento en torno a la noción de enfermedad, al ser un producto al que el fabricante le confiere propiedades curativas o preventivas, de tal forma que tiene como finalidad primordial la protección de la salud de los consumidores frente a las consecuencias nocivas de los medicamentos y frente a otro tipo de productos que se pudieran presentar como tales. El segundo criterio (medicamentocomposición) considera la función o finalidad del producto como un criterio objetivo basado en las cualidades intrínsecas del producto, de tal forma que tiene por objeto englobar los productos cuyas propiedades farmacológicas hayan sido probadas científicamente y que están destinados realmente a establecer un diagnóstico médico o a restablecer, corregir o modificar las funciones fisiológicas. A nuestro entender, existe un tercer criterio de tipo formal o administrativo (medicamento-autorización), ya que la aprobación y fijación de las condiciones en las que el medicamento puede ser puesto a disposición del consumidor dependen de la autorización administrativa sanitaria, que constituye el elemento formal del concepto jurídico de medicamento.

Si bien estos son los tres criterios que tratan de acotar el carácter amplísimo de las definiciones legales de medicamento configuradas por el legislador, es posible estudiar el medicamento como producto (esto es, concebido como producto comercializado con fines sanitarios), como servicio (es decir, por derivación y como consecuencia de lo anterior, se regula la profesión farmacéutica, que es el cauce que posibilita la dispensación de los medicamentos a los pacientes en las oficinas de farmacia) y como prestación (por la posición que ocupa dentro del sistema sanitario público, ya que la prestación farmacéutica comprende los medicamentos y productos sanitarios y el conjunto de actuaciones encaminadas a que los pacientes los reciban de forma adecuada a sus necesidades clínicas, en las dosis precisas según sus requerimientos individuales, durante el período de tiempo adecuado y al menor coste posible para ellos y para la comunidad).

Todo lo anteriormente expuesto nos conduce a la posibilidad de abordar el estudio del medicamento desde una dimensión medioambiental que, desde la

Medicamentos biosimilares: régimen jurídico y garantías sanitarias, Thomson Reuters Aranzadi, Pamplona, 2021. 
perspectiva de su impacto en el medio ambiente, toma como punto de partida básico una realidad indiscutible: el medicamento es susceptible de convertirse en residuo (medicamento como residuo).

Sin duda, nos encontramos ante un objeto de estudio muy específico que, a pesar de su gran relevancia, tal vez debido a la compleja problemática jurídica que plantea el tratamiento residual de los medicamentos, ha sido objeto de una escasa atención por parte de la doctrina. En consecuencia, es evidente que se trata de una materia que, en la praxis, plantea importantes dilemas, interrogantes y retos a futuro, a los que el Derecho debe ofrecer una rápida y adecuada respuesta.

Con todo, un correcto entendimiento de las cuestiones ambientales pasa por asumir el carácter multidisciplinar de las mismas, por lo que no resulta difícil conjugar con naturalidad la vertiente sanitaria del medicamento con su vertiente medioambiental ${ }^{29}$, y ello a pesar de la complejidad que reviste en el plano normativo y programático disciplinar todas estas cuestiones, así como el diseño, planificación y desarrollo de un óptimo marco normativo.

\section{b) La legislación ambiental.}

En el último siglo, los residuos han cobrado una gran importancia debido, entre otras razones, a su creciente acumulación como consecuencia de la cada vez mayor concentración de la población en las grandes urbes, principalmente de los países desarrollados ${ }^{30}$. En nuestro país, las empresas gestoras de residuos urbanos recogieron 21,9 millones de toneladas en el año 2016, lo que en términos per capita arroja el resultado de 471,0 kilogramos de residuos por persona y año, incrementándose en un $1 \%$ con respecto al año anterior ${ }^{31}$.

\footnotetext{
29 Sobre el enfoque multidisciplinar que requiere el planteamiento y la solución de los problemas ambientales, son interesantes los matices que ya apuntaba, hace casi cuatro décadas, Fernando López Ramón: "Ideas acerca de la intervención administrativa sobre el medio ambiente", Documentación administrativa, núm. 190, 1981 (Ejemplar dedicado a Ecología y Medio Ambiente), pp. 39-56.

30 Vid. Alicia Pérez Torres y Vicente J. Baixauli Fernández: "Tratamiento residual de los medicamentos (I). Envases y residuos", Offarm, Vol. 20, núm. 4, abril 2001, p. 114.

31 Vid. el Informe elaborado por el INE: España en..., cit., pág. 9, disponible en la página web oficial del INE: https://www.ine.es [online, consultado 26-09-2021].
} 
El incremento constante y progresivo en el volumen de residuos y de residuos de envases que diariamente se generan ha venido planteando un importante problema medioambiental, al que los poderes públicos han tratado de dar solución a través de diferentes normas jurídicas y en diversos momentos temporales; normas todas ellas que resultan de entera aplicación a los medicamentos y productos farmacéuticos, y de las que se dará cuenta seguidamente.

En el marco europeo cabe mencionar la Directiva 94/62/CE, del Parlamento Europeo y del Consejo, de 20 de diciembre de 1994, relativa a los envases y a los residuos de envases ${ }^{32}$. Del tenor literal de esta norma se deduce que su aprobación ya se justificaba a finales de la década de los noventa del siglo pasado en la necesidad de "armonizar las diversas medidas nacionales sobre gestión de envases y residuos de envases, con el fin de evitar o reducir su impacto ambiental, por una parte, proporcionando así un elevado nivel de protección del medio ambiente". Considera que "el modo mejor de prevenir la creación de residuos de envases es reducir la cantidad global de envases", y que esa reducción "es una condición necesaria del crecimiento sostenible" referido en los Tratados europeos. Dentro de la actualización de las Directivas en materia de medio ambiente que la Unión Europea ha llevado a cabo, la citada norma fue modificada en el año 2018 por la Directiva (UE) 2018/852 del Parlamento Europeo y del Consejo, con el objetivo de prevenir o reducir todo impacto de los envases y residuos de envases en el medio ambiente.

En el año 1997 se aprobó la todavía hoy vigente Ley 11/1997, de 24 de abril, de Envases y Residuos de Envases, con el objetivo de "prevenir y reducir el impacto sobre el medio ambiente de los envases y la gestión de los residuos de envases a lo largo de todo su ciclo de vida". Para alcanzar los anteriores objetivos la citada Ley estableció medidas destinadas, como primera prioridad, a la prevención de la producción de residuos de envases y, en segundo lugar, a la reutilización y reciclaje de los envases y residuos de envases, con la finalidad de evitar o reducir su eliminación. Es decir, pretendía lograr una reducción en origen de la

32 DOCE núm. L 365/10, de 31-12-1994. 
producción de residuos, apostando por el reciclaje, recuperación y valorización, e impuso unos límites o unos objetivos a cumplir en unos plazos determinados.

Un año después, en 1998, se aprobó la hoy derogada Ley 10/1998, de 21 de abril, de Residuos ${ }^{33}$, con el objeto de "prevenir la producción de residuos, establecer el régimen jurídico de su producción y gestión y fomentar, por este orden, su reducción, su reutilización, reciclado y otras formas de valorización, así como regular los suelos contaminados, con la finalidad de proteger el medio ambiente y la salud de las personas", tal y como así reza su art. 1.1.

Otro de los hitos normativos viene representado por la aprobación de la Directiva 2006/12/CE del Parlamento Europeo y del Consejo, de 5 de abril de 2006, relativa a los residuos ${ }^{34}$, que vino a establecer el marco legislativo para la manipulación de residuos en el marco europeo. En ella se definieron diferentes conceptos y se establecieron los requisitos esenciales para la gestión de residuos, en particular la obligación de que a las entidades o empresas que lleven a cabo operaciones de gestión de residuos se les haya otorgado una autorización o estén registradas, la obligación de que los Estados miembros tengan planes de gestión de residuos, y otros principios fundamentales, como son la obligación de manipular los residuos de manera que no causen un impacto negativo en el medio ambiente y la salud, el fomento de la aplicación de la jerarquía de residuos y, de conformidad con el principio "quien contamina paga", el requisito de que los costes de la eliminación de los residuos recaiga sobre el poseedor de los residuos o el anterior poseedor, o el fabricante del producto del que proceden los residuos.

Posteriormente, la Directiva 2008/98/CE, del Parlamento Europeo y del Consejo, de 19 de noviembre de 2008, sobre los residuos y por la que se derogan determinadas Directivas ${ }^{35}$ ("Directiva Marco de Residuos", DMR), trajo consigo una revisión de la Directiva anterior, desde un punto de vista de la aclaración conceptual y con un carácter ampliatorio, introduciendo un enfoque que ya tiene

\footnotetext{
${ }^{33}$ BOE de 22-04-1998.

${ }^{34}$ DOUE de 27-04-2006.

35 DOUE núm. 312, de 22-11-2008.
} 
en cuenta no sólo la fase de residuo, sino todo el ciclo de vida de los productos y materiales, centrando así los esfuerzos en disminuir el impacto en el medio ambiente de la generación y gestión de residuos, lo que supone un refuerzo del valor económico de los mismos.

En el año 2011, la Ley 22/2011, de 28 de julio, de residuos y suelos contaminados $^{36}$ incorporó al ordenamiento jurídico interno la DMR, a la vez que revisó la regulación en la materia existente en España que databa del año 1998. Esta Ley supuso incorporar nuevos conceptos acuñados en el ámbito de la Unión Europea, como por ejemplo el concepto de "subproducto" y el del fin de la condición de residuo. Estos conceptos contribuyeron a delimitar la aplicación del régimen jurídico de los residuos y la ley previó su aplicación de forma armonizada en todo el territorio nacional. Incorporó también el principio de jerarquía de residuos, principio que debe imperar en la política y en la legislación de residuos al objeto de avanzar hacia una sociedad del reciclado. En un momento posterior, la Comisión Europea llevó a cabo diversos estudios que ponían de manifiesto que era necesaria una mayor armonización, así como establecer nuevos objetivos para el medio y largo plazo, con el fin de hacer un uso más eficiente de los recursos en el territorio europeo. Por ello, en el año 2015, la Comisión Europea aprobó el Plan de Acción en materia de Economía Circular ${ }^{37}$, que incluía un compendio de medidas entre las que se encontraba la aprobación de un paquete normativo que revisara las piezas clave de la normativa de la Unión Europea relativa a residuos. Así, en 2018 se aprobó la Directiva (UE) 2018/851 del Parlamento Europeo y del Consejo, de 30 de mayo de 2018, por la que se modifica la Directiva 2008/98/CE sobre los residuos ${ }^{38}$, que vino a revisar determinados preceptos de la DMR con el objetivo de avanzar en la economía circular, armonizar, mejorar la información y trazabilidad de los residuos y reforzar la gobernanza en este ámbito.

Con la idea de incorporar a nuestro ordenamiento jurídico español la Directiva aprobada en 2018, y para incluir las modificaciones que ésta última introdujo en

\footnotetext{
${ }^{36}$ BOE núm. 181, de 29-07-2011.

${ }^{37}$ COM (2015) 614 final, Bruselas, 02-12-2015.

${ }^{38}$ DOUE de 14-06-2018.
} 
la DMR, se encuentra actualmente en tramitación el Proyecto de Ley de Residuos y Suelos Contaminados ${ }^{39}$. Esta Ley en proyecto, tal y como así se desprende de su art. 1.1, tiene por objeto regular el régimen jurídico aplicable a la puesta en el mercado de productos en relación con el impacto en la gestión de sus residuos, así como el régimen jurídico de la prevención, producción y gestión de residuos, incluyendo el establecimiento de instrumentos económicos aplicables en este ámbito, y el régimen jurídico aplicable a los suelos contaminados. A renglón seguido, el apartado segundo del mismo precepto matiza que la Ley tiene por finalidad la prevención y la reducción de la generación de residuos y de los impactos adversos de su generación y gestión, la reducción del impacto global del uso de los recursos y la mejora de la eficiencia de dicho uso con el objeto de, en última instancia, proteger el medio ambiente y la salud humana y efectuar la transición a una economía circular y baja en carbono con modelos empresariales, productos y materiales innovadores y sostenibles para garantizar el funcionamiento eficiente del mercado interior y la competitividad de España a largo plazo. Esta nueva Ley supone un fortalecimiento normativo en materia de gestión de residuos y trae consigo una actualización importante de la legislación hasta el momento aprobada ${ }^{40}$. Dará lugar a una revisión, que ya se ha iniciado, de las normas reglamentarias que regulan de los diferentes flujos de residuos, y dicha revisión supondrá una concreción normativa del alcance de buena parte de las nuevas obligaciones en materia de responsabilidad ampliada del productor (RAP), además de completar la plena incorporación del paquete de Directivas de economía circular.

El Proyecto de Ley define residuo en su art. 2 ai) como "cualquier sustancia u objeto que su poseedor deseche o tenga la intención o la obligación de desechar"; concepto plenamente coincidente, por sus términos literales, con la definición contenida en la todavía vigente Ley 22/2011, de 28 de julio ${ }^{41}$. La

\footnotetext{
${ }^{39}$ El Proyecto de Ley en tramitación se encuentra publicado en el BOCG Serie A, núm. 57-1, de 28-05-2021.

40 Sobre las novedades del Proyecto de Ley de residuos, vid. Blanca Lozano Cutanda, Pedro Poveda Gómez y Eduardo Orteu Berrocal: "Principales novedades del proyecto de ley de residuos y suelos contaminados". Disponible en: https://www.ga-p.com/ [consultado 13-10-2021].

${ }^{41}$ Vid. art. 3 a) de la Ley 22/2011, de 28 de julio, de residuos y suelos contaminados.
} 
principal consecuencia que se deriva de esta conceptualización jurídica es que, siendo el medicamento un producto de consumo especial por su composición e indicación terapéutica, es susceptible asimismo de convertirse en residuo, al igual que otro tipo de productos que existen en el mercado. $Y$ en la medida en que su poseedor deseche o tenga la intención o la obligación de desechar un medicamento, nos encontramos ante un producto que puede dañar potencialmente el medio ambiente y desencadenar efectos perniciosos para la salud, si ese proceso de desecho se realiza al margen de las normas y procedimientos normativamente diseñados. De la misma manera, los residuos de medicamentos se pueden considerar un contaminante ambiental emergente por sus efectos toxicológicos sobre la salud y el medio ambiente.

Por completar el panorama descrito, debemos apuntar la existencia de una frondosa normativa autonómica dictada en materia de gestión de residuos sanitarios $^{42}$, y que también afecta a los medicamentos, sus residuos y envases, que tras ser administrados a los pacientes en el ámbito de la asistencia sanitaria tanto pública como privada, deben ser objeto de un correcto tratamiento ${ }^{43}$.

\section{c) La legislación sanitaria y farmacéutica.}

El deber general de no lesionar ni poner en peligro la salud y la integridad física de las personas integra en el ámbito del medicamento una dimensión sanitaria primordial, para lo cual el art. 43 CE atribuye a los poderes públicos la tutela de la salud pública. En desarrollo de este mandato constitucional, se proyecta la Ley 14/1986, de 25 de abril, General de Sanidad, que se encarga de regular todas las acciones tendentes a garantizar la efectividad del derecho a la protección de la salud reconocido por la Carta Magna. El punto de partida es el deber general

\footnotetext{
${ }^{42} \mathrm{~L}$ a regulación en materia de residuos sanitarios es de competencia autonómica, por lo que son las Comunidades Autónomas las que han desarrollado normativa sobre la clasificación y gestión de dichos residuos, no existiendo normativa estatal específica al respecto. Ello ha producido cierta disparidad en la clasificación de los residuos sanitarios y en las pautas de gestión a seguir, en función de cada comunidad y la normativa de desarrollo. Actualmente hay 14 comunidades autónomas que tienen legislación aprobada que regula su gestión. El régimen jurídico de la

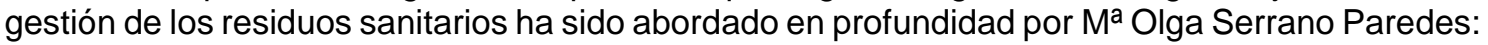
La gestión de residuos sanitarios, Comares, Granada, 2001.

${ }^{43}$ Nos referimos, principalmente, a residuos de medicamentos citotóxicos y citostáticos, además de otras categorías como, por ejemplo, residuos biosanitarios, residuos químicos, cadáveres y restos humanos, o residuos radiactivos, entre otros.
} 
de no perjudicar ni poner en riesgo la salud y la seguridad de los consumidores, lo que se traduce en el deber de poner en el mercado únicamente productos seguros. En cuanto a la seguridad en el ámbito farmacológico, de modo general se dice que un medicamento es seguro cuando ha demostrado mediante los estudios correspondientes que la relación beneficio-riesgo derivada de su administración es tal que permite su uso fiable en terapéutica a la dosis, posología y en la forma farmacéutica establecida. Los requisitos o especificaciones que debe cumplir el medicamento en relación con la seguridad se derivarán de las características de los lotes utilizados en los estudios toxicológicos y que demostraron ser aceptables. Pero la seguridad en el ámbito farmacológico, también presenta una dimensión medioambiental. El art. 12 LGURMPS, bajo la rúbrica "garantías de seguridad", advierte en su apdo. 4, que "las garantías de seguridad del medicamento se extenderán a los riesgos relativos a su utilización y, en particular, a cualquier riesgo de efectos no deseados para el medio ambiente" 44 .

Además de las garantías de calidad, seguridad y eficacia, la LGRUMPS establece como requisito para la autorización de los medicamentos la correcta identificación e información, así como las garantías de prevención de accidentes. Todos los medicamentos, una vez que han sido elaborados, deben ser sometidos a una serie de operaciones de acondicionamiento. El envasado de los medicamentos posibilita todo el desarrollo y funcionamiento del ciclo de vida del medicamento. Así, el art. 15 LGURMPS establece que los envases de medicamentos llevarán algún dispositivo de precinto que garantice al usuario que el medicamento mantiene la composición, calidad y cantidad del producto envasado por el laboratorio. Asimismo, se prevé que los embalajes deben incluir el símbolo autorizado por la Agencia Española de Medicamentos y Productos Sanitarios (AEMPS) a efectos de facilitar la aplicación y desarrollo del sistema de recogida de residuos de medicamentos y favorecer la protección del medio

\footnotetext{
${ }^{44}$ Especialmente relevante y compleja resulta esta evaluación cuando se trata de medicamentos que contienen o se componen de organismos modificados genéticamente (OMG). Precisamente por los graves e inciertos riesgos medioambientales que los mismos pueden comportar, el legislador ha establecido que dichos medicamentos sean sometidos a una evaluación similar a la prevista en la normativa sobre liberación intencional al medio ambiente de OMG; evaluación que se integra junto con la evaluación ordinaria de la calidad, la seguridad y eficacia del producto en un único procedimiento. Vid. Oriol Mir Puigpelat: Transgénicos y Derecho. La nueva regulación de los organismos modificados genéticamente, Civitas, Madrid, 2004, p. 104 y ss.
} 
ambiente. Se prevé además que todos los envases de medicamentos comercializados en España a través de las oficinas de farmacia lleven incorporado el símbolo SIGRE para indicar al paciente-consumidor que el producto se encuentra adherido a este sistema colectivo integrado de gestión (SCIG, en sus nuevas siglas), al cual aludiremos más adelante.

Finalmente, la LGURMPS, al regular el procedimiento de autorización de los medicamentos, establece en su art. 17 que en la solicitud figurarán las indicaciones sobre las medidas de precaución y de seguridad que han de adoptarse al almacenar el medicamento, al administrarlo a los pacientes y al eliminar los productos residuales, junto con la indicación de cualquier riesgo potencial que el medicamento podría presentar para el medio ambiente.

Por su parte, el Real Decreto 1345/2007, de 11 de octubre, por el que se regula el procedimiento de autorización, registro y condiciones de dispensación de los medicamentos de uso humano fabricados industrialmente ${ }^{45}$ contiene una regulación un poco más detallada, y que pretende complementar lo dispuesto en la LGURMPS. En su art. 6.5 d) contiene la obligatoriedad de adjuntar a la solicitud de autorización del medicamento una evaluación del riesgo que el producto podría representar para el medio ambiente, estableciendo, de la misma manera, la obligatoriedad de estudiar este impacto, así como de prever, caso por caso, las disposiciones particulares destinadas a limitarlo. Igualmente, el Anexo I que versa sobre "Normas y protocolos analíticos, farmacotoxicológicos y clínicos relativos a la realización de pruebas de medicamentos", contiene abundantes alusiones a la necesidad de protección del medioambiente, pero sin la necesaria concreción. El art. 62.6 del Real Decreto recoge la obligación que tiene el titular de la autorización de comercialización de un medicamento, de participar en sistemas que garanticen la recogida de los residuos de medicamentos que se generen en los domicilios; obligación que se extiende durante la vigencia de la autorización otorgada. En el anexo III, parte primera, punto 13 , de la misma norma, se especifica que, en lo referente a la información que debe figurar en el embalaje externo, se deberán incluir las precauciones especiales de eliminación de los medicamentos no utilizados y de los materiales

${ }^{45}$ BOE núm. 267, de 07-11-2007. 
de desecho derivados de su uso, cuando corresponda, y en su caso los símbolos autorizados por la AEMPS a efectos de facilitar la aplicación y desarrollo de los sistemas de recogida de medicamentos y favorecer la protección del medio ambiente. Con posterioridad a la aprobación de este Real Decreto, la AEMPS autorizó la inclusión del símbolo SIGRE en los envases de medicamentos para que los laboratorios adheridos al Sistema dieran cumplimiento a esta normativa sanitaria ${ }^{46}$.

Como se podrá observar, la legislación farmacéutica que preside el régimen de autorización de los medicamentos, liderada por la LGURMPS y su desarrollo reglamentario, contiene algunas referencias al impacto ambiental de los residuos de fármacos de uso humano y veterinario, pero no tanto respecto al embalaje ${ }^{47}$, más allá de insistir de modo abstracto y un tanto difuso, a lo largo de sus respectivos articulados, en la necesidad de preservar el medio ambiente y de evitar los riesgos que se pudieran materializar sobre el mismo. Si bien no se nos oculta que la finalidad primordial de esta normativa es establecer las garantías sanitarias de los medicamentos, no es menos cierto que las alusiones que se efectúan son genéricas, pero a la vez inherentes a la propia necesidad de proteger el medio ambiente en su conjunto, lo cual es una realidad sobradamente postulada desde antaño y por tanto está superada, en tanto insuficiente. La dimensión medioambiental del medicamento requiere cuando menos un mayor esfuerzo por parte del legislador a fin de obtener el necesario grado de concreción y determinación, lo que supone clarificar, mejorar y reforzar la normativa reguladora de la industria farmacéutica y de los medicamentos, para así lograr una adecuada conjugación entre la normativa farmacéutica y la normativa medioambiental.

\footnotetext{
46 Tal y como veremos, SIGRE es en nuestro país la entidad encargada del sistema de recogida de residuos de medicamentos. La AEMPS autorizó la inclusión del símbolo SIGRE a través de la Circular núm. 3/2013, de la AEMPS, sobre exigencia de participación en sistemas que garanticen la recogida de los residuos de medicamentos que se generen en los domicilios. Disponible

https://www.aemps.gob.es/informa/circulares/industria/2013/docs/circular 3 2013-recogidaresiduos-med.pdf

47 Así, Alejandra Boto Álvarez, en su trabajo: "Economía circular y protección de la salud", publicado en este número de la Revista.
} 


\section{LA GESTIÓN AMBIENTAL DE MEDICAMENTOS, RESIDUOS DE MEDICAMENTOS Y SUS ENVASES COMO HERRAMIENTAS PARA LA LUCHA CONTRA EL CAMBIO CLIMÁTICO.}

\section{Reciclaje farmacéutico y sostenibilidad ambiental en el contexto de una economía circular.}

La denominada economía circular constituye un marco conceptual que pretende dotar de operatividad al concepto o reto multidimensional del desarrollo sostenible ${ }^{48}$. Como señala el profesor Alenza García, la economía circular pretende superar una economía lineal caracterizada por el extraer, fabricar, comprar, usar y tirar, por un sistema económico que tenga en cuenta el ciclo de los materiales desde la producción (con un diseño ecológico de los mismos y con una innovación en los procesos industriales que garantice la obtención sostenible de materias primas y la utilización de materias primas secundarias), el consumo (que sea sostenible) y la gestión de los residuos (con ambiciosos objetivos de reutilización y reciclado) y el impulso del mercado de materias primas secundarias ${ }^{49}$.

Tiene un carácter instrumental, en la medida en que propugna una transformación de la economía y canalizarla hacia un nuevo paradigma de producción y consumo compatibles con los límites ecológicos del planeta. Además, debe tener un carácter complementario respecto de los principios jurídicos generales del ordenamiento ambiental -así como de los más específicos del Derecho de los residuos- que desde hace años vienen apuntado hacia los mismos fines que ahora persigue la economía circular ${ }^{50}$. No es, pues, un concepto tan novedoso como aparentemente se presenta, si bien está adquiriendo cada vez más visibilidad tras recorrer un largo camino hacia su

\footnotetext{
48 En este sentido, Xavier Vence Deza: "Economía circular transformadora", en: Alba Nogueira López y Xavier Vence Deza: Redondear la Economía Circular. Del discurso oficial a las políticas necesarias, Thomson Reuters-Aranzadi, Pamplona, 2021, p. 31.

${ }^{49}$ Vid. José Alenza García: "La economía circular en el Derecho ambiental", Actualidad Jurídica Ambiental, núm. 102/2, junio 2020, p. 228. Del mismo autor, un trabajo más reciente: "La dimensión jurídica del paradigma de la Economía Circular", en: Alba Nogueira López y Xavier Vence Deza: Redondear la Economía Circular..., cit., pp. 65-95.

50 lbídem.
} 
maduración y consolidación, a pesar de su indeterminación como concepto que se pretende aplicar a cada vez más ámbitos. Amén de otros antecedentes que perfilan los rasgos de la economía circular, el punto de partida oficial en el ámbito europeo viene marcado por la Comunicación de la Comisión de 2 de diciembre de 2015, titulada "Cerrar el círculo: un plan de acción de la UE para la economía circular"51. Con este plan, la Unión Europea inició un proceso de transición a una economía más circular, en la cual el valor de los productos, los materiales y los recursos se pueda mantener en la economía durante el mayor tiempo posible, y en la que se reduzca al mínimo la generación de residuos. Desde el plano medioambiental, la economía circular "pone el acento en la base material del modelo económico, en el agotamiento de recursos críticos, la contaminación, el cambio climático y la cada vez más difícil y costosa gestión de los residuos" 52 . De esta manera, se pretende alcanzar el objetivo de conseguir una "economía sostenible, hipocarbónica, eficiente en el uso de los recursos y competitiva". Este planteamiento, impulsado por la Unión Europea, forma parte de la Estrategia Europa 2020 para generar un crecimiento inteligente, sostenible e integrador.

La industria farmacéutica, al igual que el resto de sectores que conforman el tejido productivo industrial, debe comprender el papel crucial que desempeña en la ardua tarea de crear mercados y sociedades más sostenibles. Alcanzar este objetivo debe implicar la asunción de un plus de responsabilidad, con el objetivo de desarrollar estrategias que incorporen la sostenibilidad y la variable "cambio climático", y también con el fin de realizar un ejercicio valorativo para sopesar los riesgos y las oportunidades que supone ofrecer una sólida respuesta ante la problemática medioambiental en general, y del cambio climático en especial. Es posible que las empresas y multinacionales entiendan que destinar una parte de sus beneficios a la protección medioambiental sea un coste, pero no es menos cierto que a la vista de los intereses en juego, y de los bienes jurídicos objeto de protección, -que no son otros que el medio ambiente y la salud de las personas, más bien estamos ante una auténtica inversión que tiene como fundamento la

\footnotetext{
${ }^{51}$ COM (2015) 614 final, Bruselas, 02-12-2015.

52 Vid. Xavier Vence Deza: “Economía circular...", cit., p. 33.
} 
protección de dichos bienes jurídicos para las generaciones presentes y venideras $^{53}$.

Un enfoque de estas características supone materializar y consolidar, en parte, el inmenso potencial de la industria farmacéutica como importante sector de la I+D+i, que es capaz de manifestar su compromiso medioambiental y, por ende, puede crear y aportar valor a la sociedad de manera sostenible. Este planteamiento que acabamos de exponer nos conduce irremediablemente al concepto de "sostenibilidad ambiental", que no deja de ser la concreción del desarrollo sostenible en su vertiente ambiental, como principio y objetivo común de la sociedad y el mercado. Tal y como señala el profesor Sanz Larruga, la faceta ambiental de la sostenibilidad postula un nuevo modelo económico que se basa en "el respeto ambiental y el uso racional de los recursos naturales que se imponen al desarrollo económico y productivo, al que se añade su proyección hacia el futuro, de manera que no se comprometan las posibilidades de las generaciones venideras para atender a sus propias necesidades" 54 . Desde el punto de vista del Derecho Administrativo, la sostenibilidad ambiental viene a ser una aplicación de la eficacia administrativa desde la perspectiva del criterio de la eficiencia como principio de utilización racional de los recursos, hasta el punto de que su impacto ha impregnado una parte considerable de la ordenación jurídico-administrativa sectorial y particularmente la regulación de los diferentes recursos naturales (biodiversidad, suelo, aguas, aire, etc. ${ }^{55}$. Por ello, la sostenibilidad ambiental tiene una gran proyección sobre el régimen jurídico de

\footnotetext{
${ }^{53}$ Según el Informe elaborado por el INE: España en..., cit., p. 9, disponible en la página web oficial del INE: https://www.ine.es [online, consultado 26-09-2021], el gasto de la industria en protección ambiental alcanzó en el año 2016 los 2.490 millones de euros (casi un 5\% más que el año anterior).

54 Vid. Francisco Javier Sanz Larruga: "Sostenibilidad ambiental y Derecho Administrativo: ¿nuevo remedio ante la crisis económica o una exigencia constitucional? A propósito de la nueva Ley de Economía Sostenible", Actualidad Jurídica Ambiental, núm. 2, mayo de 2011, pp. 10-16. Asimismo, sobre el origen y evolución de los conceptos de desarrollo sostenible y de sostenibilidad, puede consultarse: José Alenza García: "Desarrollo sostenible", en José Antonio Santamaría Pastor: Los principios jurídicos del Derecho Administrativo, La Ley, Madrid, 2010, pp. 1388-1426; Juan Cruz Alli Aranguren: "Del desarrollo sostenible a la sostenibilidad. Pensar globalmente y actual localmente", Revista de Derecho Urbanístico y Medio Ambiente, núm. 226, 2006, pp. 139-211. Sobre la incidencia que ha tenido el Derecho europeo en la recepción de la sostenibilidad en el ordenamiento jurídico español, vid. Jesús Jordano Fraga: "La Administración en el Estado ambiental de Derecho", RAP, núm. 173, 2007, pp. 101-141.
}

55 Vid. Francisco Javier Sanz Larruga: "Sostenibilidad ambiental y Derecho Administrativo...", cit. 
los diferentes sectores regulados, incluida la fabricación industrial de medicamentos y productos farmacéuticos, en la medida en que está actualmente presente en toda la actividad pública y privada desde la perspectiva del impacto ambiental. Asimismo, tal y como veremos, impregna cada vez más la Responsabilidad Social Corporativa (RSC) de la industria farmacéutica, y las estrategias por parte de las compañías que integran el sector.

Pero la consideración de principios jurídicos ambientales, como el de sostenibilidad, no resulta incompatible con la aplicación de la circularidad al sector farmacéutico, sobre todo en el plano de la prevención-anticipación, la aminoración de residuos generados, su adecuado tratamiento, o en materia de ecodiseño de medicamentos y optimización de sus envases. En este sentido, cabría apuntar la necesidad de instaurar mejores técnicas de racionalización en el proceso de fabricación de los medicamentos, tanto en el acondicionamiento primario como en el acondicionamiento secundario de los mismos (el material de acondicionamiento se clasifica en primario o secundario, según esté o no en contacto con el producto), entre otros aspectos ${ }^{56}$.

Resulta incontestable que el sector farmacéutico debe caminar en esta dirección, aportando su contribución a este modelo de economía circular, y avanzando en la consolidación de este aparente nuevo paradigma, que todavía precisa de una mayor concreción, especialmente en el ámbito de la salud y de los medicamentos. Aun con todo, no se nos oculta que el modelo de desarrollo económico presente en nuestra sociedad, que se fundamenta en una utilización intensiva de los recursos, la producción de residuos y la contaminación que resulta de la misma, no es a largo plazo sostenible. El tránsito hacia un nuevo modelo basado en la eficiencia en el uso de los recursos y la gestión de los residuos va a ser uno de los grandes retos a los que deberá enfrentarse la industria farmacéutica europea y a nivel global. Desde esta óptica, una gestión

\footnotetext{
56 Alejandra Boto Álvarez: "Economía circular y protección...", cit., alude a aspectos fundamentales de la circularidad del sector farmacéutico, como, por ejemplo, "el ajuste de las dosis, y la racionalidad del empaquetado, pues es habitual no sólo que haya sobrantes que desechar, sino también que el medicamento se componga, a veces injustificadamente, de envase externo, prospecto y blíster interno".
} 
eficiente de los residuos facilitará la mitigación de las emisiones de GEI y favorecerá una adecuada transición energética.

\section{La Responsabilidad Ampliada del Productor (RAP) aplicada al ciclo de vida del medicamento.}

\section{a) Hacia una producción de medicamentos más verde y sostenible.}

La Responsabilidad Ampliada del Productor (RAP), con origen en el marco jurídico de los residuos, pretende contribuir a la gestión solvente de los materiales, facilitar el reciclaje y promover el diseño ambiental de los productos con el fin de reducir el impacto ambiental que genere el producto después de su vida $^{57}$. Así, la problemática que plantean los residuos se hace recaer sobre el fabricante de un producto, lo que ha llevado al desarrollo de técnicas encaminadas al tratamiento, que tienen en consideración la modulación de los precios de los productos en función del material que se pretenda recuperar, cuyos residuos al final de su vida útil se tratan de solventar mediante el reciclaje. Esta solución contemplada en la normativa europea, y también recogida en la normativa española sobre residuos, envases y residuos de envases, parece ser insuficiente para alcanzar de forma completa los objetivos de la economía circular. La reducción es uno de los parámetros que integran la filosofía de la economía circular, dentro de la jerarquía de la gestión de los residuos, pero lo cierto es que existen dificultades para lograrla, pues el mercado prosigue estando orientado a la demanda (consumo), y no se establecen incentivos suficientes que permitan desarrollar tecnologías encaminadas a minimizar la producción de residuos.

La normativa española reguladora de la RAP se centra fundamentalmente en la última fase del ciclo de vida del producto, esto es, cuando este se convierte en residuo, sin dedicar la atención debida a las fases previas de diseño, producción y consumo, los cuales forman parte de la política de prevención de la generación de residuos $^{58}$. La fase de diseño de un medicamento es tremendamente importante, pues la adecuada selección de las materias primas en esa fase

\footnotetext{
57 Vid. Aitana De La Varga Pastor: "La responsabilidad ampliada del productor...”, cit. p. 203.

${ }^{58}$ Ibídem, p. 207.
} 
previa será determinante para lograr un uso más eficiente de los materiales, seleccionar los menos dañinos para el medio ambiente y maximizar la eficiencia de todos los procesos de fabricación, reduciendo así la producción de residuos. De la misma forma, la fase de fabricación industrial de los medicamentos requiere obtener el mayor rendimiento posible de las materias primas y de la energía disponible, lo que, a su vez, como todo proceso industrial, tiene como consecuencia inherente la generación de residuos a modo de emisiones atmosféricas, vertidos, pérdida de energía, etc. Tras el consumo del medicamento, debe dársele el destino final adecuado a modo de residuo, de tal forma que la eficiencia en el ecodiseño del mismo debería posibilitar una reducción casi total de la generación de residuos del producto. El problema se plantea cuando el paciente-consumidor de medicamentos se aparta con toda indiferencia del sistema de gestión instaurado, y desecha los medicamentos acumulados o caducados por otras vías que producen daños irreparables tanto al medio ambiente como a la salud de las personas.

Sin perder de vista que, de modo primario, recae sobre la industria farmacéutica el compromiso de caminar hacia una producción de medicamentos más verde y sostenible, minimizando los impactos medioambientales y así favorecer una mejor gestión de los residuos farmacéuticos, sería positivo un refuerzo de medidas de incentivación en cada una de las fases -sobre todo en las fases previas- del ciclo de vida del medicamento. De la misma manera, la Administración debe fomentar el uso racional de los medicamentos, de tal forma que se estimule un uso y consumo responsables, lo cual redundaría positivamente y desde el origen en la protección del medio ambiente.

\section{b) La Responsabilidad Ampliada del Productor (RAP) en el ámbito de la gestión de los residuos de medicamentos y sus envases.}

En nuestro país, la gestión integral de los medicamentos, los residuos de medicamentos y sus envases, se viene configurando como un sistema de corresponsabilidad social, fomentándose la participación activa, conjunta, diferenciada y coordinada de los fabricantes de medicamentos, importadores, distribuidores, gestores de residuos, Administraciones públicas competentes, y consumidores. Aunque sea desde un punto de vista estético, la gestión del sistema parece inspirarse -aparentemente- en los principios de la 
responsabilidad compartida. En el proceso de reciclaje farmacéutico intervienen diversos actores. Por un lado, la industria farmacéutica, que con su modelo de I+D+i es uno de los sectores clave para lograr el cumplimiento de los objetivos de protección medioambiental y desarrollo sostenible. Seguidamente, la distribución farmacéutica es un sector que también desempeña un papel activo en este proceso, pues acomete la labor de retirar los envases vacíos o con restos de medicamentos que los ciudadanos depositan en las farmacias. El papel de la farmacia comunitaria en la gestión de medicamentos es igualmente digno de mención, ya que las oficinas de farmacia son receptoras de los residuos de medicamentos, envases de medicamentos, medicamentos caducados, o incluso medicamentos devueltos por los pacientes (que no se pueden poner de nuevo en el circuito) y que son depositados por los ciudadanos en el punto de depósito de la farmacia, para su posterior entrega al gestor competente. Pero no será ese el único proceso en el que intervienen. En un proceso que difiere del anterior, también efectúan la oportuna retirada de medicamentos (previa a su dispensación), como consecuencia de la revisión de medicamentos caducados que no resulta de interés mantener entre las existencias por el motivo que sea, así como los derivados de vigilancia y alertas sanitarias emitidas por las autoridades. Por otro lado, y partiendo de que está en manos del legislador europeo y nacional la consolidación de un marco jurídico claro, que integre adecuadamente la dimensión sanitaria y medioambiental del medicamento, es normal que las Administraciones públicas cuenten con la colaboración de otras personas o entidades para el cumplimiento de los fines públicos, lo cual no debe afectar en modo alguno a la asunción de sus responsabilidades. El refuerzo de su compromiso de mejorar la gestión de los residuos farmacéuticos, así como la implacable exigencia a todos los operadores del cumplimiento de los requisitos legales y de gestión que la normativa impone, son parámetros imprescindibles de la actuación administrativa. En la gestión integral de residuos farmacéuticos, -sobre todo en el ámbito sanitario y asistencial-, también desempeñan una función relevante las empresas privadas dedicadas al tratamiento de este tipo de residuos mediante procesos que, con toda seguridad, son altamente tecnificados y automatizados. Finalmente, no podemos olvidar la responsabilidad que tienen los pacientes-consumidores en un uso y consumo responsable de los medicamentos, además de que su colaboración con la cadena de reciclaje 
farmacéutico, -depositando envases y medicamentos en los puntos habilitados-, reducirá sustancialmente el impacto ambiental de estos productos sobre el medio ambiente.

A la vista está que no todos los agentes intervinientes asumen fáctica y legalmente las mismas obligaciones, ni tampoco las obligaciones asumidas por cada uno de los agentes son sustituibles o reemplazables. Tan es así que el propio concepto de RAP ya nos conduce a la idea de que el productor debe responsabilizarse de su producto hasta el final del proceso, sin que en este objetivo sea sustituido por pacientes-consumidores y Administraciones públicas. En este contexto cabe situar y resaltar el protagonismo adquirido por los SIG (que pueden ser sistemas tanto individuales como colectivos), dentro del marco organizativo de este tipo de sistemas que despliegan su operatividad para diferentes tipos de productos. En el sector farmacéutico se ha traducido en la implantación, hace ya veinte años, de un SIG con el fin de garantizar la correcta gestión medioambiental de los medicamentos, restos de medicamentos de origen doméstico, y sus envases. Nos referimos a la entidad "SIGRE Medicamento y Medio Ambiente, S.L.", una entidad privada nacida del producto de la colaboración entre laboratorios, distribuidores y oficinas de farmacia, cuya actividad se centra en el reciclaje y tratamiento medioambiental de envases y residuos de medicamentos ${ }^{59}$. A través de un sistema de logística inversa, esta entidad viene facilitando que los ciudadanos puedan depositar medicamentos caducados, envases o restos de medicamentos, para su tratamiento posterior. La distribución farmacéutica se responsabiliza de la retirada, transporte y custodia de los residuos de envases y restos de medicamentos que los ciudadanos depositan en los Puntos SIGRE de la farmacia. Una vez recogidos, en cualquiera de las visitas que realizan a la farmacia diariamente, son trasladados a sus almacenes y depositados allí en contenedores estanco,

\footnotetext{
${ }^{59}$ Vid. Aitana De La Varga Pastor: "La responsabilidad ampliada del productor...", cit. p. 225-226. Esta autora señala que las organizaciones que a modo de SCRAP se encargan de la gestión de los residuos de envases en España (en especial la de envases de plástico, Ecoembes), han sido duramente criticadas por el hecho de funcionar a modo de monopolio, y porque se lucran, a pesar de ser entidades sin ánimo de lucro, por lo que entiende necesario el "control y supervisión de estas organizaciones, en el sentido que apunta la nueva normativa, así como el establecimiento de objetivos propios concretos y no solo los genéricos que establece la DMR en cómputos totales".
} 
ubicados a su vez en una zona especialmente identificada de sus instalaciones y separada de los productos farmacéuticos ${ }^{60}$. Este sistema se identifica con los actuales sistemas colectivos (SCRAP), que tras sometimiento a autorización y transcurrida su vigencia, se ha adaptado a la nueva normativa y a la nueva nomenclatura que abandona los SIG para referirse a los sistemas colectivos como SCRAP.

El sistema cerrado de logística inversa implantado por SIGRE permite mantener los residuos de medicamentos y sus envases dentro del control del canal farmacéutico, hasta su entrega a los correspondientes gestores de residuos autorizados. Según destaca la propia entidad, esto conlleva una serie de ventajas socio-sanitarias (evita accidentes, sustracciones, tráfico ilícito y falsificaciones) y medioambientales (menor impacto ambiental asociado al transporte de los residuos). De igual modo, se afirma que la aplicación de la inteligencia artificial y la robótica en la separación y clasificación de los residuos SIGRE, está mejorando los porcentajes de recuperación y reciclaje, contribuyendo a la economía circular ${ }^{61}$ y a la disminución de GEI62.

Con todos los avances experimentados hasta el momento, -muy loables, por cierto-, el sector farmacéutico se encuentra en un momento clave de transición hacia la consolidación de una auténtica economía circular, por lo que será muy importante la materialización de las previsiones contenidas en las nuevas normas, y su posterior desarrollo reglamentario. Así sucede, a modo de ejemplo, con la adaptación del régimen jurídico de la RAP a la modificación de la DMR, que es uno de los aspectos más destacados del Proyecto de Ley de Residuos.

\footnotetext{
60 Según datos de la Memoria SIGRE 2020, "este proceso de logística inversa ofrece grandes ventajas medioambientales (se calcula un ahorro de 1.400 toneladas de $\mathrm{CO}_{2}$ anuales) y de eficiencia económica, además de garantizar el control de los residuos por los agentes legalmente autorizados para la distribución y dispensación de los medicamentos". Memoria SIGRE de Sostenibilidad 2020, disponible en: https://www.sigre.es/ [consultado: 12-10-2021].

61 Vid. Memoria SIGRE de Sostenibilidad 2020, cit.

62 El sistema SIGRE se halla inscrito en el "Registro de huella de carbono, compensación y proyectos de absorción de $\mathrm{CO}_{2}$ " del Ministerio para la Transición Ecológica y ha obtenido el "Sello de cálculo de huella de carbono". Este Registro recoge los esfuerzos que las entidades inscritas en él realicen para calcular, reducir y compensar las emisiones de gases de efecto invernadero que se generen con motivo de su actividad. Puede consultarse la Página web del Ministerio para la Transición Ecológica y el Reto Demográfico: https://www.miteco.gob.es/es/cambioclimatico/temas/mitigacion-politicas-y-medidas/registro-huella.aspx
} 
La nueva norma sienta unas bases normativas más completas que comprenden, entre sus aspectos más novedosos, un incremento de la transparencia en el funcionamiento, la rendición de cuentas y la representatividad de los productores en la toma de decisiones de los sistemas colectivos de RAP como las relativas a un renovado sistema de cobertura de costes del sistema de RAP y al llamado ecodiseño (que se presenta ahora como una herramienta clave para facilitar los procesos de preparación para la reutilización, reciclado y valorización de los residuos).

En lo que a envases de medicamentos se refiere, la Directiva (UE) 2018/852, de 30 de mayo, sobre envases, expone que la mayoría de los Estados miembros ya cuenta con regímenes de RAP para los envases, pero advierte que al existir grandes disparidades en lo que se refiere a estructura, eficiencia y alcance "las normas relativas a la RAP establecidas en la Directiva 2008/98/CE de 19 de noviembre deben aplicarse a los regímenes de RAP para productores de envases". Por ello, no tendrán un régimen diferenciado, sino el mismo que el genérico al que se deberán adaptar antes del 31 de diciembre de 2024. El Estado español se encuentra preparando una normativa nueva que acogerá y adaptará estos regímenes, lo que es urgente dado el incremento exponencial del número de envases que diariamente se manejan. Ello exige, entre otras cuestiones, poner el foco de atención en medidas preventivas, actualizando el régimen de RAP de los envases y residuos de envases ${ }^{63}$.

\section{c) Autorregulación y Responsabilidad Social Corporativa (RSC) de la industria farmacéutica como componentes que permiten el diseño de estrategias sostenibles.}

Pero además de la necesaria intervención administrativa que preside el sector farmacéutico, anteriormente analizada, y que se traduce en la existencia de un régimen jurídico regulador de la misma, la responsabilidad social corporativa (RSC) de las empresas farmacéuticas es un componente de categoría a la hora de diseñar estrategias sostenibles en el ámbito de la fabricación de medicamentos a gran escala. La RSC va referida a la toma de conciencia y

\footnotetext{
${ }^{63}$ Vid. Aitana De La Varga Pastor: "La responsabilidad ampliada del productor...", cit., pp. 225-
} 226. 
asunción de responsabilidad por parte de las empresas en relación con las consecuencias e impacto que sus actividades y decisiones proyectan en tres dimensiones principales: medioambiental, social y ética ${ }^{64}$. Resulta evidente la conexión existente entre la fabricación de medicamentos y las tres dimensiones mentadas, de tal manera que es lógico que las empresas de este sector incluyan estas cuestiones en su RSC. En cualquier caso, no ha de excluirse que otras empresas u organizaciones no estrictamente dedicadas a la producción de medicamentos tengan también en consideración el impacto de sus decisiones y actividad en el plano medioambiental ${ }^{65}$. Esta RSC implica que las empresas deben dar cuenta en sus informes anuales acerca de su actividad en relación con las tres dimensiones ya apuntadas, de tal forma que se configuran como una herramienta fundamental también en el plano de la rendición de cuentas, en la medida en que no son documentos meramente informativos ${ }^{66}$. Todo ello, en línea con la tendencia actual a superar la tradicional idea de voluntariedad asociada a la responsabilidad social corporativa. No ofrece dudas que la RSC afianza la posición estratégica de una empresa en el mercado, mejora su reputación en el contexto social y refuerza la captación de clientes socialmente responsables. El problema ha venido siendo el debate sobre el carácter de la misma, esto es, su obligatoriedad o voluntariedad a la hora de ser aplicada en las empresas ${ }^{67}$.

En lo que aquí interesa destacar, pondremos varios ejemplos. Según noticia publicada en el diario EL GLOBAL ${ }^{68}$, la compañía Roche se ha unido a la

\footnotetext{
64 Vid. Laura Salamero Teixidó: "El desperdicio de alimentos", en: Laura Salamero Teixidó (Dir.): Manual Básico de Derecho Alimentario, Tirant Lo Blanch, Valencia, 2019, p. 136.

65 Es el caso, por ejemplo, de empresas dedicadas a la prestación de servicios sanitarios, que cuenten con servicios de farmacia hospitalaria, o que puedan, cuando menos, gestionar los residuos sanitarios o farmacéuticos, o sus envases, de una forma respetuosa con el medio ambiente.
}

${ }^{66}$ Vid. Laura Salamero Teixidó: “El desperdicio de...”, cit., p. 137.

${ }^{67}$ Así, la Ley 11/2018 de información no financiera y diversidad en España introdujo la obligación para las empresas de más de 250 trabajadores desde 2021 de informar sobre "la evolución, los resultados y la situación del grupo, y el impacto de su actividad respecto, al menos, a cuestiones medioambientales y sociales, al respeto de los derechos humanos y a la lucha contra la corrupción y el soborno".

68 Vid. El Global: "Roche fomenta la lucha contra el cambio climático y la protección ambiental entre sus empleados", publicado en fecha 14-01-2021. Disponible en: https://elglobal.es/ 
iniciativa EverGreener, que tiene como objetivo fomentar la lucha contra el cambio climático y la protección del medio ambiente entre su plantilla, apostando por una reducción del nivel de emisiones de dióxido de carbono $\left(\mathrm{CO}_{2}\right)$. La compañía señala que han experimentado un descenso de dichas emisiones del $67 \%$ por empleado desde el año 2004, propiciado por la reducción del consumo de energía y del uso de combustibles fósiles. Asimismo, aboga por no compensar las emisiones de $\mathrm{CO}_{2}$, sino reducir activamente estas emisiones, hasta el punto de reducirlas a cero para el año 2050. Para alcanzar estos objetivos, la compañía ha establecido una hoja de ruta basada en mejorar las operaciones y el uso de energía por empleado mientras que, en un segundo paso, se pretende sustituir la energía restante con energía generada a partir de fuentes sostenibles.

Otro ejemplo lo podemos encontrar en la compañía española Grupo Almirall, que dispone de una estrategia de sostenibilidad ESG (en inglés, acrónimo de "medio ambiente, social y de gobierno corporativo"), implementada a través de quince áreas de trabajo, de entre las que se incluye el medio ambiente, la cual se concreta en tres objetivos: a) continuar con el desarrollo de la estrategia de lucha contra el cambio climático; b) detallar el cálculo y la mejora de la huella de carbono; $y, c)$ incrementar la gestión de la eficiencia energética ${ }^{69}$.

Por su parte, la compañía biomédica Pfizer ha presentado en el mes de julio de 2021 la Memoria de Sostenibilidad en España correspondiente al ejercicio 2020, un año marcado por la pandemia. En ella se resumen los hitos, planes, acciones y proyectos que se han llevado a cabo en las distintas esferas: científica, económica, social y medioambiental y, en lo que aquí interesa destacar, la compañía manifiesta que ha adoptado medidas encaradas a eliminar las barreras a la eficiencia energética, implementar energías renovables y planificar de forma estratégica y a largo plazo las alternativas energéticas. La compañía señala que, otro de los logros conseguidos y bajo el compromiso de minimizar las emisiones de GEI generadas en el desarrollo de sus actividades, es que,

69 Vid. Informe de gestión Grupo Almirall 2020-Anexo I, disponible a texto completo en su página web corporativa: http://www.almirall.es [consultado 01-10-2021]. 
tanto en las oficinas centrales como en las delegaciones, ha logrado reducir un $32,8 \%$ las emisiones de $\mathrm{CO}_{2}{ }^{70}$.

\section{A MODO DE CONCLUSIÓN.}

La actividad de la industria farmacéutica, al igual que el resto de actividades humanas e industriales, tienen un considerable impacto en el medio ambiente y los recursos naturales, que a lo largo de las últimas décadas se ha intentado minimizar a través de diferentes instrumentos, dando paso a una normativa medioambiental cada vez más rigurosa, con una mejora de la eficiencia energética, y una innovación en los procesos de fabricación de medicamentos que se apartan radicalmente de los tradicionales cánones de contaminación.

Los medicamentos poseen unas características intrínsecas que los hacen diferenciarse de otro tipo de productos de consumo ordinario. Ello justifica la tradicional intervención administrativa de orden sanitario, muy intensa, siendo el sector farmacéutico uno de los sectores más reglamentados. A la triple exigencia de que los medicamentos sean seguros, eficaces y de calidad demostrada para cada uno de los pacientes a los que se les administren, hemos de añadir la exigencia de que los medicamentos deben ser respetuosos con el medio ambiente. Esto supone un reconocimiento de la dimensión medioambiental del medicamento, no en pocas ocasiones descuidada por el legislador, a pesar de que el binomio salud y medio ambiente son las dos caras de la misma moneda. Esta consideración medioambiental de los medicamentos exige una adecuada conjugación de la legislación sanitaria y farmacéutica con la legislación medioambiental, para lo cual deviene imprescindible la adopción de un enfoque integrado, pero que tenga en consideración las especificidades del medicamento como producto, y las particularidades del sector farmacéutico. Será necesario, por tanto, seguir avanzando hacia un marco jurídico más concreto, detallado e interconectado, que establezca una adecuada relación entre la logística industrial de los medicamentos y la necesidad de preservar el medio ambiente, con especial referencia a la problemática del cambio climático, a lo que se une

\footnotetext{
70 De la misma manera, Pfizer planea implantar una planta fotovoltaica en la planta biotecnológica entre 2021 y 2022 que sea capaz de generar $2.700 \mathrm{MWh}$, reduciendo las emisiones de $\mathrm{CO}_{2}$ en aproximadamente 700 toneladas. La Memoria de Sostenibilidad de Pfizer en España correspondiente al ejercicio 2020 puede descargarse en https://www.pfizer.es [consultado 10-012021].
} 
la necesidad de desarrollar la reciente Ley de Cambio Climático. Estrategias como la economía circular, las inversiones verdes y la reducción de emisiones deberán formar parte del eje vertebral de la normativa europea y española.

La gestión de medicamentos, residuos de medicamentos y sus envases constituye un proceso complejo. Sin duda, la aprobación de un nuevo marco normativo en materia de residuos es un avance que merece una valoración positiva, si bien todavía existen aspectos necesitados de clarificación y mejora. Es precisa la adopción de un enfoque más global, que tenga en consideración al medicamento en especial, y todo el ciclo de vida del medicamento, dedicando la atención debida a las fases previas de diseño, producción y consumo, lo que permitirá a su vez definir adecuadamente los costes que en el sistema de RAP deben asumir los productores. En todo caso, la normativa medioambiental especialmente la relativa a gestión de residuos y envases, con evidentes repercusiones para el sector farmacéutico, deberá proporcionar a futuro las exigencias de seguridad jurídica necesarias para garantizar el correcto funcionamiento de dicho sector en el marco del Estado y del mercado interior. Sobre todo, el posterior desarrollo reglamentario será determinante para definir el alcance de las nuevas obligaciones que la legislación implementa, como así sucede con la necesidad de mayor concreción de la RAP o una mayor revisión de los SCRAP a fin de incrementar la transparencia mediante obligaciones de control y supervisión de estas organizaciones.

Con todo, a la vista están los notables esfuerzos desplegados por la industria farmacéutica y los SCRAP en su compromiso por consolidar el tránsito a una economía circular que permita incrementar el desarrollo de medicamentos más verdes y sostenibles. Estos agentes, en el desarrollo de una actividad industrial que es esencial, y a la vez depende de servicios ecosistémicos y recursos naturales, se encuentran en un momento clave para aplicar de forma reforzada criterios de circularidad, así como reforzar estrategias sostenibles que apuesten seriamente por la preservación del medio ambiente, lo que sin duda reducirá el impacto sobre el cambio climático.

\section{BIBLIOGRAFÍA.}


Alenza García, José: "La dimensión jurídica del paradigma de la Economía Circular", en: Nogueira López, Alba y Vence Deza, Xavier: Redondear la Economía Circular. Del discurso oficial a las políticas necesarias, Thomson Reuters-Aranzadi, Pamplona, 2021, pp. 65-95.

Alenza García, José: "La economía circular en el Derecho ambiental", Actualidad Jurídica Ambiental, núm. 102/2, junio 2020, pp. 225-249.

Alenza García, José: "Desarrollo sostenible", en José Antonio Santamaría Pastor: Los principios jurídicos del Derecho Administrativo, La Ley, Madrid, 2010, pp. 1388-1426.

Alli Aranguren, Juan-Cruz: "Del desarrollo sostenible a la sostenibilidad. Pensar globalmente y actual localmente", Revista de Derecho Urbanístico y Medio Ambiente, núm. 226, 2006, pp. 139-211.

Almirall: Informe de gestión Grupo Almirall 2020-Anexo I, disponible en: http://www.almirall.es

Arévalo Moscoso, Roberto Olvi: "La Industria y sus efectos en el cambio climático global", Revista Científica de Investigación-Actualización del Mundo de las Ciencias, Vol. 2, núm. 2, junio, 2018, pp. 595-611.

Bombillar Sáenz, Francisco Miguel: Intervención administrativa y régimen jurídico del medicamento en la Unión Europea, Tesis Doctoral, Universidad de Granada, 2010.

Boto Álvarez, Alejandra: "Economía circular y protección de la salud", publicado en este número de la Revista.

Ciscar Martínez, Juan Carlos y Soria Ramírez, Antonio: "La política climática", Papeles de la Economía Española núm. 121/2009, pp. 45-53.

De La Varga Pastor, Aitana: "La responsabilidad ampliada del productor y la economía circular en la UE y en el ordenamiento jurídico español", en: Nogueira López, Alba y Vence Deza, Xavier: Redondear la Economía Circular. Del discurso oficial a las políticas necesarias, Thomson Reuters-Aranzadi, Pamplona, 2021, pp. 203-234. 
El Global: "Roche fomenta la lucha contra el cambio climático y la protección ambiental entre sus empleados", publicado en fecha 14-01-2021. Disponible en: https://elglobal.es/

Escrig Zaragozá, José Daniel: "El impacto ambiental de las actividades industriales: el cambio necesario", Universidad Internacional de Andalucía, España, 2008, pp. 55-63.

Ezquerra Huerva, Antonio: "La Ordenación Farmacéutica", en: Pemán Gavin, Juan Mำ (Dir.): Derecho sanitario aragonés. Estudios sobre el marco jurídico de la sanidad en Aragón. Vol. II, Cortes de Aragón, Zaragoza, pp. 291-369.

Flórez Belledo, Jesús (Dir.): Farmacología Humana, Masson, Barcelona, 2005.

Fundación Weber: El valor del medicamento desde una perspectiva social, Madrid, marzo de 2021, disponible en: https://www.farmaindustria.es

Hernández Corchete, Juan Antonio: "Los Hábitos Energéticos en el horizonte del desarrollo sostenible: una panorámica de los esfuerzos por invertir la tendencia de emisión de GEI como medio de atajar el preocupante proceso de cambio climático", en: Utrera Caro, Sebastián y Piñar Mañas, José Luis (Coords.): Desarrollo Sostenible y Protección del Medio Ambiente, Civitas, Madrid, 2002, pp. 311-318.

INE: España en cifras 2019, disponible en: https://www.ine.es

Jordano Fraga, Jesús: "La Administración en el Estado ambiental de Derecho", RAP, núm. 173, 2007, pp. 101-141.

Lobo Aleu, Félix: "Introducción a la regulación del sector farmacéutico en España", en: Faus Santasusana, Jordi y Vida Fernández, José (Dirs.): Tratado de Derecho Farmacéutico, Thomson Reuters Aranzadi, Pamplona, 2017, pp. 7995.

López-Jurado Escribano, Borja y Ruiz de Apodaca Espinosa, Ángel: La autorización ambiental integrada. Estudio sistemático de la Ley 16/2002, de prevención y control integrados de la contaminación, Civitas, Madrid, 2002.

López Ramón, Fernando: "Ideas acerca de la intervención administrativa sobre el medio ambiente", Documentación administrativa, núm. 190, 1981 (Ejemplar dedicado a Ecología y Medio Ambiente), pp. 39-56. 
Lozano Cutanda, Blanca y Alli Turrillas, Juan-Cruz: Administración y legislación ambiental, 5ª ed., Dykinson, Madrid, 2009.

Lozano Cutanda, Blanca; Poveda Gómez, Pedro y Orteu Berrocal, Eduardo: "Principales novedades del proyecto de ley de residuos y suelos contaminados"; disponible en: https://www.ga-p.com/

Martín Mateo, Ramón: "El derecho de la atmósfera", RAP, núm. 121, Madrid, 1990, pp. 89-148.

Mir Puigpelat, Oriol: Transgénicos y Derecho. La nueva regulación de los organismos modificados genéticamente, Civitas, Madrid, 2004.

Noguera Peña, Alfonso y Del Castillo Rodríguez, Carlos: Medicamentos biosimilares: régimen jurídico y garantías sanitarias, Thomson Reuters Aranzadi, Pamplona, 2021.

Parejo Navajas, Teresa: "Gobernar el cambio climático", en: Parejo Alfonso, Luciano (Dir.): El Derecho ante la innovación y los riesgos derivados del cambio climático, Tirant Lo Blanch, Valencia, 2015.

Pérez Torres, Alicia y Baixauli Fernández, Vicente J.: "Tratamiento residual de los medicamentos (I). Envases y residuos", Offarm, Vol. 20, núm. 4, abril 2001, pp. 114-122.

Pfizer: Memoria de Sostenibilidad 2020, disponible en: https://www.pfizer.es

Razquin Lizarraga, Martín Mạ: "Energía y Medio Ambiente: marco normativo y aplicación judicial", Revista Aranzadi de Derecho Ambiental, núm. 21, 2012, pp. 23-60.

Rivero Ortega, Ricardo: "Los gases de efecto invernadero: Inspección y control de riesgos en materia de emisiones contaminantes", Noticias de la Unión Europea, núm. 258, 2006 (Ejemplar dedicado a: Gases de Efecto Invernadero), pp. 79-84.

Salamero Teixidó, Laura: "El desperdicio de alimentos", en: Salamero Teixidó, Laura (Dir.): Manual Básico de Derecho Alimentario, Tirant Lo Blanch, Valencia, 2019. 
Sanz Larruga, Francisco Javier: "Sostenibilidad ambiental y Derecho Administrativo: ¿nuevo remedio ante la crisis económica o una exigencia constitucional? A propósito de la nueva Ley de Economía Sostenible", Actualidad Jurídica Ambiental, núm. 2, mayo de 2011, pp. 10-16.

Sarasíbar Iriarte, Miren: Régimen jurídico del cambio climático, Lex Nova, Valladolid, 2006.

Sarrato Martínez, Luis: Régimen jurídico-administrativo del medicamento, La Ley Wolters-Kluwer, Madrid, 2015.

Sarrato Martínez, Luis: La responsabilidad administrativa, civil y penal en el ámbito del medicamento, Thomson Reuters- Aranzadi, Pamplona, 2014.

Serrano Paredes, Mํㅡㄹ Olga: La gestión de residuos sanitarios, Comares, Granada, 2001.

Sigre: Memoria Sigre de Sostenibilidad 2020, disponible en: https://www.sigre.es Vence Deza, Xavier: "Economía circular transformadora”, en: Nogueira López, Alba y Vence Deza, Xavier: Redondear la Economía Circular. Del discurso oficial a las políticas necesarias, Thomson Reuters-Aranzadi, Pamplona, 2021, pp. 31 64.

Vida Fernández, José: Concepto y Régimen Jurídico de los Medicamentos, Tirant lo Blanch, Valencia, 2015. 